\title{
Repurposing Artemisia annua L. Flavonoids, Artemisinin and Its Derivatives as Potential Drugs Against Novel Coronavirus (SARS - nCoV) as Revealed by In-Silico Studies
}

\author{
Krishna Kumar Rai ${ }^{1}$, Apoorva1, Lakee Sharma ${ }^{1}$, Neha Pandey ${ }^{1,2}$, Ram Prasad Meena ${ }^{1}$, \\ Shashi Pandey Rai ${ }^{*}$ \\ ${ }^{1}$ Laboratory of Morphogenesis, Centre of Advance Study in Botany, Department of Botany, Institute of Science, Banaras Hindu \\ University (BHU), Varanasi-221005 (Uttar Pradesh), India \\ ${ }^{2}$ Department of Botany, CMP PG College, University of Allahabad, Prayagraj, India
}

Article Information
Received: 04 November 2020
Revised version received: 25 November 2020
Accepted: 30 November 2020
Published: 28 December 2020
Cite this article as:
K.K. Rai et al. (2020) Int. J. Appl. Sci. Biotechnol. Vol
8(4): $374-393$. DOI: $10.3126 / i j a s b t . v 8 i 4.33667$
*Corresponding author
Prof. Shashi Pandey Rai,
Centre for Advance Study in Botany Department of
Botany, Institute of Science, Banaras Hindu University,
Varanasi, India
Email: shashi.bhubotany@gmail.com/
$\quad$ p.shashi@bhu.ac.in
Peer reviewed under authority of IJASBT
() 2020 International Journal of Applied Sciences and
Biotechnology
This is an open access article \& it is licensed under a Creative
(https://creativecommons.org/licenses/by-nc/4.0/)
Keywords:

\begin{abstract}
Coronavirus-induced COVID-19, a highly contagious respiratory illness first originated from Wuhan city of Hubei province, China, and has affected 235 countries across the globe. The COVID-19 is mainly transmitted by the droplets of an infected person when they cough, sneeze, or exhale. Currently, there are no specific drugs licensed for the effective treatment or prevention of COVID19 and the treatment is mainly focused on controlling symptoms. Identification of small bioactive plant molecules that specifically target whole viral replication apparatus have great potential towards the development of antiviral drug discovery. This communication describes our current understanding of SARS-nCoV interaction with some herbal bioactive compounds of A. annua including sesquiterpenes, flavonoids and phenolics using in silico approach.
\end{abstract}

Keywords: SARS-nCoV; Artemisinin; Artesunate; Remdesvir; in-silico analysis

\section{Introduction}

Deadly SARS-nCoV has created serious attention worldwide as there are currently no effective therapeutic drugs for treating COVID-19 coronavirus infections to date (Gao et al., 2020). Seeing serious health emergencies throughout the globe we systematically analyzed the genome of SARS-nCoV. The genome of this virus is peptidoglycan enveloped, positive-sense, single-stranded RNA beta-coronavirus. The whole-genome sequence of 
2019-nCoV (Severe acute respiratory syndrome coronavirus 2 isolate Wuhan-Hu-1, GenBank: MN908947.3) indicates that this new coronavirus has four catalytic sites of the enzymes that can be utilized as antiviral targets because they are highly conserved, and have high sequence similarity with the viruses causing severe acute respiratory syndrome (SARS) and the Middle East respiratory syndrome (MERS) (Gao et al., 2020). Furthermore, 2019-nCoV virus protein structural analyses revealed that major drug-binding pockets in enzymes are highly conserved across 2019-nCoV, MERS, and SARS (Xu et al., 2020). Although the disease SARS and MERS have been reported to have higher mortality rate than the COVID-19. Yet COVID-19 is highly infectious because the SARS-nCoV virus is highly contagious and spreads more easily among people, leading to increased fatality around the globe.

Similar to SARS and MERS, the SARS-nCoV open reading frame, ORF1a encoding non-structural proteins (such as 3chymotrypsin-like protease, papain-like protease), ORF1 b encoding RNA-dependent RNA polymerase and helicases and ORF for spike glycoprotein and other accessory structural proteins (Fig. 1) (Li et al., 2016). Several options and studies for emerging infections of SARS-nCoV, including small-molecule drugs, monoclonal antibodies, oligonucleotide-based vaccines, peptides, interferon therapies are being suggested by many health professionals (Wu et al., 2020). The drug therapies that act on the coronavirus based on the mode of action can be divided into following groups based on the target of specific pathways: (1) by blocking the virus from binding to human cell receptors, (2) by preventing the virus RNA synthesis and replication; (3) by improving host's innate immunity; and (4) by preventing virus entry to the host's cells (Fig. 2). However, new interventions related to target the genome of SARS-nCOV are likely to require several months or years to develop (Xu et al., 2020).

The ongoing SARS-nCoV pandemic makes us painfully realizethat our current known options for the treatment of this highly infectious life-threatening zoonotic new coronavirus infections are very limited (Bogoch et al., 2020). Therefore, there is an urgent need for specific drugs that can efficiently block the processing of virus, replication, modification, and infection along with the ability to boost host immunity (Hui et al., 2020). The SARS-nCoV enters into its host cell by the attachment of its S-glycoprotein through the receptor-binding domain (RBD) to a membrane protein that acts as a first receptor (human ACE2) on the host's surface. Among them, the 3C-like main protease (3CLpro), Papain-like proteinase (PLpro), RNA dependent RNA polymerase (RdRp), helicase, capsid, and spike proteins/enzymes are the major targets for the development of small-molecule inhibitors as a potential $\operatorname{drug}(\mathrm{Wu}$ et al., 2020). As therapeutic options in response to COVID-19 are urgently needed, we analyzed the potential of some Artemisia annua derived bioactive compounds and their conjugates that are already established as an antimalarial agent and have antiviral and immunomodulatory potential too. Interestingly, in the recent years, the bioactive components of $A$. annua herb such as artemisinin, beta-arteether, flavanoids and phenolic compound along with its semisynthetic derivatives such as artesunate and artemether have proven its efficiency as an antiviral agent. It has proven its efficacy against human cytomegalovirus, herpes simplex virus type 1, Epstein-Barr virus, hepatitis $\mathrm{B}$ virus, hepatitis $\mathrm{C}$ virus, bovine viral diarrhea virus and various other viral diseases. In this study an in-silico approach has been exploited to attest the efficacy of several bioactive compounds of A. annua along with artemisinin and its derivatives against SARS-nCoV.

\section{Materials and Methods}

\section{Sequence Retrieval of SARS-nCoV, Human ACE2 Receptor and Data Collection}

The complete genome of "severe acute respiratory syndrome coronavirus 2 isolate Wuhan-Hu-1" was downloaded from NCBI GenBank https://www.ncbi.nlm.nih.gov/genbank/, accession no. MN908947.3 (Li and Clercq, 2020) and the native crystal structure of the human ACE2 extracellular domain (PDB code: 1R42) were downloaded from the protein data bank (PDB). The viral whole genome has been divided majorly into 3 open reading frames (ORFs) by NCBI ORF- Finder i.e. ORF1a containing Protease domain, ORF1b containing RNA dependent RNA polymerase and Helicase domain, and last coding region contained Spike and other associated structural proteins (Fig. 1). Each ORF was extracted from the whole genome of 2019-nCoV and translated by employing a translational tool of ExPASy server (Gasteiger et al., 2003). Further, each protein sequences were aligned individually to search the homologs as well as paralogues by BLASTp program https://blast.ncbi.nlm.nih.gov/Blast.cgi. To analyze the functional domains, different tools were used such as SMART http://smart.embl-heidelberg.de/, NCBI CDD https://www.ncbi.nlm.nih.gov/Structure/cdd/cdd.shtml, and Pfam https://pfam.xfam.org/. Further other physicochemical properties of the proteins were characterized including isoelectric point, GRAVY (grand average of hydropathicity) https://www.bioinformatics.org/sms2/protein_gravy.html (Stothard, 2000). 


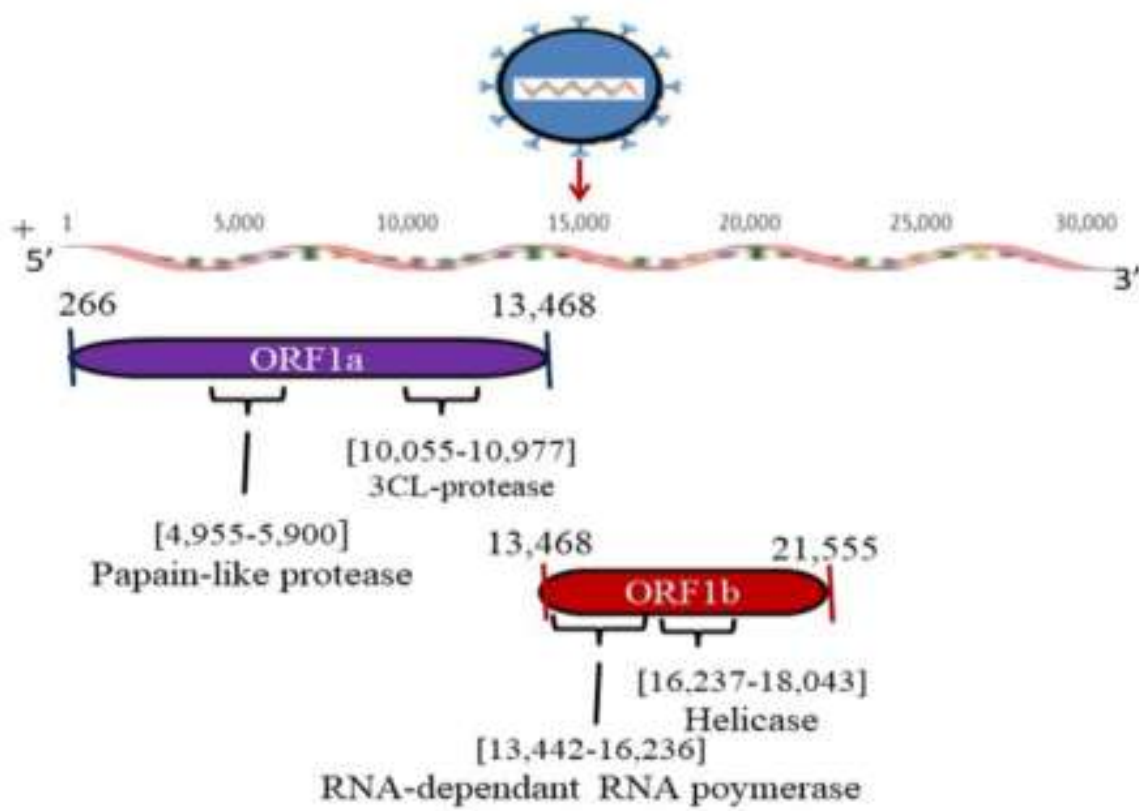

29,674

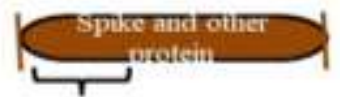

$[21,563-25,384]$

Spike

Fig. 1: Overall genome and nucleotide sequences responsible for coding different ORFs of SARS-nCoV. The large replicase polyprotein ORFab with the purple rectangle showing PLpro, and 3CLpro and the residues that bound the individual proteins/domains. Red rectangle showing ORF1b that includes RNA dependent RNA polymerase and helicase and brown rectangle showing sequences responsible for spike and other glycoproteins.

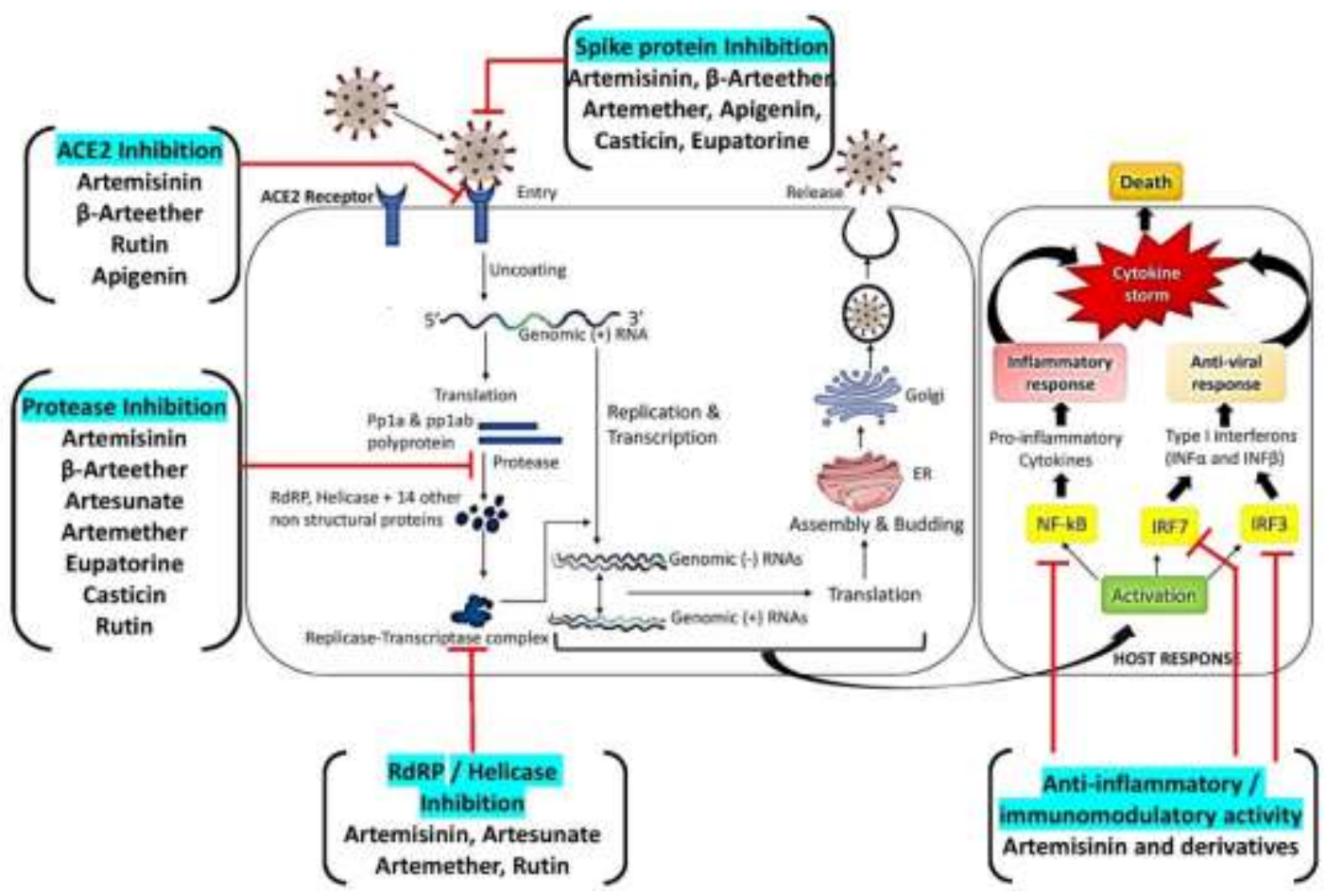

Fig. 2: Proposed model for Artemisinins (artemisinin and its derivatives) and flavonoids from Artemisia annua as potential candidate drugs for SARS-CoV-2 treatment therapy. ACE2 receptor inhibition, spike protein inhibition, protease inhibition, helicase inhibition and RNA polymerase (RdRP) inhibition are various mechanisms of action for artemisinins and flavonoids of Artemisia аппиа. Artemisinins also exhibit anti-inflammatory responses by targeting inflammatory networks including NF-kB, IRF3 and IRF7 and may prevent cytokine storm which is the leading cause of death in Covid19 patients. 


\section{Structural Modelling and Analysis}

Once the genomic sequences were analyzed and validated, those were further divided into fragments, according to the proteins. In our work we have dissected the genome into 5 parts: $1^{\text {st }}$ denoting the translation of whole CDS (ORF1a), $2^{\text {nd }}$ denoting helicase, $3^{\text {rd }}$ RNA polymerase, $4^{\text {th }}$ spike protein, and $5^{\text {th }}$ glycoprotein portion of 2019-nCov. Experimentally resolved templates (based on X-ray diffraction and NMR parameters) were obtained by SWISSMODEL; https://swissmodel.expasy.org/, a homology modelling tool (Waterhouse et al., 2018). Templates having a maximum identity and query coverage were selected for 3D modeling. 3D structure of all the five proteins was modelled in intensive mode with the hidden Markov model (HMM) by employing Phyre2 server (Kelley et al., 2015). 3-D model having minimum DOPE score were further refined by ModRefiner server https://zhanglab.ccmb.med.umich.edu/ModRefiner/ using two-step Atomic-level Energy Minimization (Xu and Zhang, 2011). All models were validated RAMPAGE http://mordred.bioc.cam.ac.uk/ rapper/ and ProSA web servers (Widerstein and Sippl, 2007).

\section{Active Site Analysis}

Active pockets of the modeled proteins were predicted by analyzing the sites and amino acid residues participating actively in covalent and non- covalent interactions with ligands using Metapocket 2.0 server (Huang, 2009) which characterize topology of the functional domains of query protein by other predictors like LIGSITE ${ }^{\text {cs }}$, PASS, QSiteFinder, SURFNET, Fpocket, GHECOM, ConCavity, and POCASA. The final selection of ligand binding sites on the protein surface was done based on the Z- score.

\section{Preparation of Ligand Database and Molecular Docking}

In this work, we have selected 4 test ligands which are either natural or derivative bioactive compounds of Artemisia апnиа. The ligands are- artemisinin (CID: 68827), betaartether (CID: 107929), artesunate (CID: 6917864), and artemether (CID: 68911), while the control ligand was set to remdesivir (CID: 121304016). With the help of PubChem database https://pubchem.ncbi.nlm.nih.gov (Kim et al., 2019), target ligands were drawn using ChemDraw software

https://www.perkinelmer.com/category/chemdraw. All the docking calculations were executed by employing the Patchdock server in which receptor and ligands were docked having local molecular shape complementarity (Duhoyny et al., 2002). Based on the area, score, and ACE (Atomic Contact Energy) value, the results were visualized in both 3D and 2D format to locate the binding site of ligands on the receptor surface and to identify the potential amino acid residues that are involved in the interaction.

\section{Results and Discussion}

Artemisinin and its derivatives have been already known for their powerful outstanding bioactivity, tolerability, and relative affordability. These properties of proven effective safety and availability make artemisinin a natural plantbased drug of special attention for various clinical studies (Chen et al., 1994; Wang et al., 2020). Indeed, its nonmalarial applications have augmented progressively over time since artemisinin was known to the world for the approved treatment of malaria. The possible use of artemisinin as anti-cancer, anti-inflammatory, anti-parasitic (other than malaria), and anti-viral roles have been also discovered. In addition, flavonoids of A. аппиа are also known for various biological activities including anti-tumor (Razak et al., 2019), anti-inflammatory and immunomodulatory activities (Laavola et al., 2012). Here, in this paper, we analyzed some auspicious research in artemisinin and flavonoids repurposing, especially for COVID-19 treatments, as a window that can help future drug development processes for this pandemic (Ho et al., 2012).

\section{Sequence Retrieval and Ligand Database}

Artemisinin and its derivatives are sesquiterpene lactones that bear the 1,2,4-trioxane moiety having endoperoxide bridge which is essential for the effective pharmacological activity of artemisinin and its chemical derivatives (Zhou $e t$ al., 2020). In this paper, we have tested several ligands that are natural/derivatized bioactive compounds of a Chinese medicinal plant Artemisia аппиа. These ligands are artemisinin, betaartether, artesunate and artemether. In addition, apigenin, casticin, chrysophanol, eupatorin, limonene, pinene, rosmarinic acid and rutin were also tested while the control ligand was set as remdesivir, hydroxychloroquine and ivermectin (Table 1). Remdesivir is a nucleoside analogue that acts as RdRp inhibitorwhere as hydroxychloroquine (HCQ) which is an analogue of chloroquine has been widely known to act as immunomodulator and Ivermectin is basically an antiparasitic drug use to treat skin infection and cutaneous diseases. However, compared to remdesvir, both HCQ and Ivermectin also have antiviral properties which have also shown promising results in the preliminary treatment of SARS-nCoV. On January 31, 2020, the New England Journal of Medicine reported the diagnosis and treatment of the first SARS-nCoV patient by Remdesivir which showed some effective possibility in the treatment of the novel coronavirus infected individuals. Recently, several researchers have confirmed the antiviral effect of HCQ which was effective in the preventing the progression and infection SARS-nCoV disease (Zhou et al., 2020). Similarly, Yao et al. (2020) has designed and optimized the respective doses of HCQ for the treatment of SARS-nCoV. The mechanism by which HCQ is being effective for the treatment of SARS-nCoV is that it is able to regulate various post-translational modification processes particularly 
glyosylation of angiotensin-converting enzyme 2 (ACE 2) with in the host cell as well able to cleave SARS-nCoV spike protein thereby preventing the binding of SARSnCoV virus to the receptor protein (Yao et al., 2020). On the contrary, researchers have also indicated promising effect of Ivermectin in treating SARS-nCoV disease as it has shown to inhibit replication of SARS-nCoV under in-vitro condition (Caly et al., 2020). Similarly, Lv et al. (2018) has also demonstrated the inhibitory effect of Ivermectin on importin- $\alpha / \beta$-dependent nuclear transport viral proteins thus inhibiting the entry of virus into the host cell.

Table 1: Details of the selected phytocompounds used in this study with their PubChem IDs.

\begin{tabular}{|c|c|c|c|c|}
\hline Compound name & Mol. formula & $\begin{array}{l}\text { Mol. Wt. } \\
\text { (g/mol) }\end{array}$ & 2D structure & PubChem ID \\
\hline
\end{tabular}

\section{Terpenes:}

\begin{tabular}{|c|c|c|c|}
\hline Artesunate & $\mathrm{C}_{19} \mathrm{H}_{28} \mathrm{O}_{8}$ & 384.421 & 6917864 \\
\hline Artemether & $\mathrm{C}_{16} \mathrm{H}_{26} \mathrm{O}_{5}$ & 298.37 & 68911 \\
\hline Betaartether & $\mathrm{C}_{34} \mathrm{H}_{56} \mathrm{O}_{10}$ & 624.8 & 3037930 \\
\hline Limonene & $\mathrm{C}_{10} \mathrm{H}_{16}$ & 136.23 & 22311 \\
\hline Pinene & $\mathrm{C}_{10} \mathrm{H}_{16}$ & 136.23 & 6654 \\
\hline
\end{tabular}

\section{Flavanoids}

Apigenin

$\mathrm{C}_{15} \mathrm{H}_{10} \mathrm{O}_{5}$

270.05

5280443<smiles>O=c1cc(-c2ccc(O)cc2)oc2cc(O)cc(O)c12</smiles> 
Table 1: Details of the selected phytocompounds used in this study with their PubChem IDs.

\begin{tabular}{|c|c|c|c|c|}
\hline Compound name & Mol. formula & $\begin{array}{l}\text { Mol. Wt. } \\
\text { (g/mol) }\end{array}$ & 2D structure & PubChem ID \\
\hline Casticin & $\mathrm{C}_{19} \mathrm{H}_{18} \mathrm{O}_{8}$ & 374.34 & & 5315263 \\
\hline Chrysophanol D & $\mathrm{C}_{15} \mathrm{H}_{10} \mathrm{O}_{4}$ & 254.24 & y & 10208 \\
\hline Eupatorin & $\mathrm{C}_{18} \mathrm{H}_{16} \mathrm{O}_{7}$ & 344.3 & & 97214 \\
\hline Rutin & $\mathrm{C}_{27} \mathrm{H}_{30} \mathrm{O}_{16}$ & 610.5 & & 5280805 \\
\hline
\end{tabular}

\section{Phenolic Compounds:}

Rosmarinic acid $\mathrm{C}_{18} \mathrm{H}_{16} \mathrm{O}_{8} \quad 360.3$

\section{Recommended drugs as control}

Hydroxychloroquine $\quad \mathrm{C}_{18} \mathrm{H}_{26} \mathrm{ClN}_{3} \mathrm{O}$


Table 2 Patchdock results showing interaction of Artemisia annua flavanoids, artemisinin and its derivatives with different selected ORFs

\begin{tabular}{|c|c|c|c|c|c|c|c|}
\hline \multicolumn{8}{|c|}{ A. Results showing interaction of drugs with $1^{\text {st }}$ strand ORF 1a } \\
\hline S. no. & $\begin{array}{l}\text { Receptor + } \\
\text { ligand }\end{array}$ & $\begin{array}{l}\text { Active } \\
\text { pocket } \\
\text { involved }\end{array}$ & $\begin{array}{l}\text { Amino acids } \\
\text { involved in } \\
\text { interaction }\end{array}$ & Score & Area & $\begin{array}{l}\text { ACE } \\
\text { value }\end{array}$ & $\begin{array}{l}\text { Other surrounding } \\
\text { residues }\end{array}$ \\
\hline 1. & $\begin{array}{l}\text { Protease (ORF } \\
1 \mathrm{a})+ \\
\text { artemisinin }\end{array}$ & $1^{\text {st }}$ & $\begin{array}{l}\mathrm{HIS}^{2352} \text {, } \\
\mathrm{CYS}^{2456} \text {, } \\
\text { MET }^{2360} \text {, } \\
\mathrm{HIS}^{2474} \text {, } \\
\mathrm{HIS}^{2475} \text {, } \\
\text { MET }^{2476} \text {, } \\
\text { GLU }^{2477}\end{array}$ & 3592 & 407.60 & -176.24 & $\begin{array}{l}\text { LEU }^{2338}, \mathrm{PHE}^{2451} \text {, } \\
\mathrm{GLY}^{2454}, \mathrm{SER}^{2455}\end{array}$ \\
\hline 2. & $\begin{array}{l}\text { Protease (ORF } \\
1 \text { a) }+ \\
\text { betaartether }\end{array}$ & $1^{\mathrm{st}}$ & $\begin{array}{l}\text { LEU }^{2452} \text {, } \\
\text { ASN }^{2453}, \\
\text { CYS }^{2456} \text {, } \\
\text { HIS }^{2352} \text {, } \\
\text { HIS }^{2474} \text {, } \\
\text { HIS }^{2475} \text {, } \\
\text { MET }^{2476} \text {, } \\
\text { GLU }^{2477}\end{array}$ & 4220 & 487.00 & -212.11 & $\begin{array}{l}\text { PHE }^{2451}, \text { GLY }^{2454} \text {, } \\
\text { SER }^{2455}, \text { HIS }^{2474}\end{array}$ \\
\hline 3. & $\begin{array}{l}\text { Protease (ORF } \\
1 \mathrm{a})+ \text { artesunate }\end{array}$ & $1^{\text {st }}$ & $\begin{array}{l}\mathrm{HIS}^{2352}, \\
\text { MET }^{2360}, \\
\text { GLY }^{2454}, \\
\text { CYS }^{2456}, \\
\text { GLU }^{2477}\end{array}$ & 4536 & 500.20 & -190.81 & $\begin{array}{l}\text { THR }^{2337}, \text { LEU }^{2338} \text {, } \\
\text { HIS }^{2475}\end{array}$ \\
\hline 4. & $\begin{array}{l}\text { Protease (ORF } \\
\text { 1a) + artemether }\end{array}$ & $1^{\text {st }}$ & $\begin{array}{l}\text { HIS }^{2352} \text {, } \\
\text { MET }^{2360}, \\
\text { ASN }^{2453} \\
\text { CYS }^{2456} \text {, } \\
\text { HIS }^{2474} \text {, } \\
\text { HIS }^{2475}, \\
\text { MET }^{2476}, \\
\text { GLU }^{2477} \\
\text { GLN }^{2500}\end{array}$ & 3854 & 459.20 & -150.20 & $\begin{array}{l}\text { PHE }^{2451}, \text { GLY }^{2454} \text {, } \\
\text { SER }^{2455}\end{array}$ \\
\hline 5. & $\begin{array}{l}\text { Protease (ORF } \\
1 \mathrm{a})+ \text { Casticin }\end{array}$ & $1^{\mathrm{st}}$ & $\begin{array}{l}\text { THR }^{24,25,26,} \\
\text { CYS }^{44} \text {, } \\
\text { THR }^{45} \text {, } \\
\text { SER }^{46} \text {, } \\
\text { MET }^{50}\end{array}$ & 4344 & 518.80 & -256.33 & $\begin{array}{l}\mathrm{LEU}^{141}, \mathrm{ASN}^{142}, \\
\mathrm{GLY}^{143}, \mathrm{SER}^{144} \\
\mathrm{HIS}^{164}, \mathrm{MET}^{165}\end{array}$ \\
\hline 6. & $\begin{array}{l}\text { Protease (ORF } \\
\text { 1a) }+ \\
\text { Chrysophanol D }\end{array}$ & $1^{\text {st }}$ & $\begin{array}{l}\text { GLN }^{2500}, \\
\text { GLU }^{2477}, \\
\text { MET }^{2476}, \\
\text { ASN }^{2453}, \\
\text { HIS }^{2474}\end{array}$ & 3716 & 424.40 & -181.37 & $\begin{array}{l}\mathrm{LEU}^{2452}, \mathrm{ARG}^{2499} \text {, } \\
\mathrm{HIS}^{2352}, \mathrm{PHE}^{2451} \text {, } \\
\mathrm{GLY}^{2454}\end{array}$ \\
\hline 7. & $\begin{array}{l}\text { Protease (ORF } \\
\text { 1a) + Eupatorin }\end{array}$ & $1^{\mathrm{st}}$ & $\begin{array}{l}\text { GLY }^{2382}, \\
\text { VAL }^{2384}, \\
\text { MET }^{2328}, \\
\text { ALA }^{2381}, \\
\text { LYS }^{2408}\end{array}$ & 4514 & 520.20 & -185.43 & $\begin{array}{l}\mathrm{GLY}^{2431}, \mathrm{SER}^{2432}, \\
\mathrm{ASN}^{2406}, \mathrm{TRP}^{2342}, \\
\mathrm{PRO}^{2407}\end{array}$ \\
\hline 8. & $\begin{array}{l}\text { Protease (ORF } \\
\text { 1a) + Pinene }\end{array}$ & $1^{\mathrm{st}}$ & $\begin{array}{l}\mathrm{ASN}^{2462}, \\
\mathrm{ILE}^{2417}, \\
\mathrm{GLN}^{2421}, \\
\mathrm{THR}^{2422}\end{array}$ & 2716 & 281.00 & -71.72 & $\begin{array}{l}\mathrm{PHE}^{2319}, \mathrm{THR}^{2603}, \\
\mathrm{ASP}^{2606}, \mathrm{PHE}^{2605}\end{array}$ \\
\hline 9 & $\begin{array}{l}\text { Protease (ORF } \\
1 \text { a) }+ \\
\text { Rosmarinic acid }\end{array}$ & $1^{\mathrm{st}}$ & $\begin{array}{l}\mathrm{TYR}^{2465}, \\
\mathrm{PHE}^{2605}, \\
\mathrm{THR}^{2422}, \\
\mathrm{ASN}^{2462}, \\
\mathrm{ASP}^{2464}\end{array}$ & 4594 & 533.80 & -105.49 & $\begin{array}{l}\text { THR }^{2603}, \mathrm{GLN}^{2421} \text {, } \\
\text { PHE }^{2423}, \mathrm{PHE}^{2319}\end{array}$ \\
\hline 10. & $\begin{array}{l}\text { Protease (ORF } \\
\text { 1a) + Apigenin }\end{array}$ & $1^{\mathrm{st}}$ & $\begin{array}{l}\text { GLN }^{2503}, \\
\text { GLU }^{2477}, \\
\text { ARG }^{2499}, \\
\text { VAL }^{2497} \\
\text { PHE }^{2496}\end{array}$ & 4048 & 458.50 & -141.64 & $\begin{array}{l}\text { HIS }^{2352}, \text { GLN }^{2500} \\
\text { THR }^{2501}, \text { LEU }^{2478}\end{array}$ \\
\hline 11. & $\begin{array}{l}\text { Protease (ORF } \\
\text { 1a) + Linonene }\end{array}$ & $1^{\mathrm{st}}$ & $\begin{array}{l}\text { ALA }^{2381} \\
\text { GLY }^{2382} \\
\text { LYS }^{2408} \\
\text { PRO }^{2407}\end{array}$ & 4160 & 482.10 & -216.83 & $\begin{array}{l}\mathrm{SER}^{2432}, \mathrm{GLY}^{2431} \\
\mathrm{PRO}^{2433}, \mathrm{MET}^{2328} \\
\mathrm{TRP}^{2342}\end{array}$ \\
\hline
\end{tabular}




\begin{tabular}{|c|c|c|c|c|c|c|c|}
\hline 12. & $\begin{array}{l}\text { Protease (ORF } \\
\text { 1a) + Rutin }\end{array}$ & $1^{\mathrm{st}}$ & $\begin{array}{l}\text { MET }^{2476}, \\
\text { THR }^{2336}, \\
\text { THR }^{2337}, \\
\text { HIS }^{2352}, \\
\text { MET }^{2360}\end{array}$ & 4194 & 532.30 & -263.46 & $\begin{array}{l}\mathrm{ARG}^{2499}, \mathrm{ASP}^{2498}, \\
\mathrm{VAL}^{2497}, \mathrm{THR}^{2335}, \\
\mathrm{GLY}^{2454}\end{array}$ \\
\hline 13 & $\begin{array}{l}\text { Protease (ORF } \\
\text { 1a) }+ \\
\text { Remdesivir }\end{array}$ & $1^{\mathrm{st}}$ & $\begin{array}{l}\mathrm{HIS}^{2352}, \\
\text { MET }^{2360}, \\
\text { LEU }^{2361}, \\
\text { GLY }^{2454} \\
\text { GLN }^{2500}\end{array}$ & 6064 & 865.80 & -422.56 & $\begin{array}{l}\text { THR }^{2336}, \text { LEU }^{2452}, \\
\text { CYS }^{2456}\end{array}$ \\
\hline 14. & $\begin{array}{l}\text { Protease }(\mathrm{ORF} \\
\text { 1a) } \\
+ \text { Hydroxychlor } \\
\text { oquine }\end{array}$ & $1^{\mathrm{st}}$ & $\begin{array}{l}\text { ASP }^{142} \\
\text { GLY }^{143} \\
\text { SER }^{144} \\
\text { CYS }^{145}\end{array}$ & 4178 & 473.90 & -270.13 & $\begin{array}{l}\text { HIS }^{41}, \text { MET }^{50}, \\
\text { TYR }^{55}\end{array}$ \\
\hline 15. & $\begin{array}{l}\text { Protease (ORF } \\
\text { 1a) }+ \\
\text { Ivermectin }\end{array}$ & $1^{\mathrm{st}}$ & $\begin{array}{l}\text { PHE }^{144}, \\
\text { LEU }^{145}, \\
\text { ASN } \\
\text { GLY } \\
\text { GLY } \\
\text { SER } \\
148\end{array}$ & 6092 & 747.90 & -381.18 & $\begin{array}{l}\mathrm{HIS}^{162}, \mathrm{HIS}^{163}, \\
\mathrm{MET}^{164}, \mathrm{GLU}^{165} \\
\mathrm{LEU}^{166}, \mathrm{PRO}^{167}\end{array}$ \\
\hline \multicolumn{8}{|c|}{ B. Results showing interaction of drugs with RNA polymerase } \\
\hline S. no. & $\begin{array}{l}\text { Receptor + } \\
\text { ligand }\end{array}$ & $\begin{array}{l}\text { Active } \\
\text { pocket } \\
\text { involved }\end{array}$ & $\begin{array}{l}\text { Amino acids } \\
\text { involved in } \\
\text { interaction }\end{array}$ & Score & Area & $\mathbf{A C E}$ & $\begin{array}{l}\text { Other surrounding } \\
\text { residues }\end{array}$ \\
\hline 1. & $\begin{array}{l}\text { RNA } \\
\text { polymerase } \\
+ \text { artemisinin }\end{array}$ & $6^{\text {th }}$ & $\mathrm{VAL}^{317}$ & 2978 & 342.60 & -219.68 & $\begin{array}{l}\mathrm{SER}^{312}, \mathrm{PHE}^{313}, \\
\mathrm{GLY}^{314}\end{array}$ \\
\hline 2. & $\begin{array}{l}\text { RNA } \\
\text { polymerase } \\
+ \text { betaartether }\end{array}$ & $6^{\text {th }}$ & $\begin{array}{l}\text { LEU }^{257} \text {, } \\
\text { THR }^{539} \text {, } \\
\text { LYS }^{675} \text {, and } \\
\text { SER }^{680}\end{array}$ & 3274 & 341.70 & -126.14 & $\begin{array}{l}\mathrm{PRO}^{315}, \mathrm{LEU}^{316}, \\
\mathrm{VAL}^{317}\end{array}$ \\
\hline 3. & $\begin{array}{l}\text { RNA } \\
\text { polymerase } \\
\text { +artesunate }\end{array}$ & $4^{\text {th }}$ & $\begin{array}{l}\mathrm{VAL}^{191} \\
\mathrm{ASP}^{208} \\
\mathrm{PHE}^{209}\end{array}$ & 3968 & 495.60 & -215.84 & GLY $^{190}$, GLY $^{207}$ \\
\hline 4. & $\begin{array}{l}\text { RNA } \\
\text { polymerase } \\
+ \text { artemether }\end{array}$ & $6^{\text {th }}$ & $\begin{array}{l}\text { TYR }^{260} \\
\text { VAL }^{317}\end{array}$ & 3218 & 359.70 & -256.13 & $\begin{array}{l}\text { GLY }^{314}, \text { PRO }^{315} \text {, } \\
\text { LEU }^{316}\end{array}$ \\
\hline 5. & $\begin{array}{l}\text { RNA } \\
\text { polymerase } \\
+ \\
\text { Apigenin } \\
\end{array}$ & $4^{\text {th }}$ & $\begin{array}{l}\text { GLY }^{502} \\
\text { TYR }^{455} \\
\text { LYS }^{675} \\
\text { LYS }^{499}\end{array}$ & 4526 & 480.90 & -160.80 & $\begin{array}{l}\text { SER }^{680}, \text { VAL }^{666} \text {, } \\
\text { GLY }^{558}, \text { VAL }^{559}\end{array}$ \\
\hline 6. & $\begin{array}{l}\text { RNA } \\
\text { polymerase } \\
+ \\
\text { Casticin } \\
\end{array}$ & $4^{\text {th }}$ & $\begin{array}{l}\text { VAL }^{327} \\
\text { TYR }^{280}\end{array}$ & 5098 & 599.50 & -118.45 & GLY $^{290}$, GLY $^{337}$ \\
\hline 7. & $\begin{array}{l}\text { RNA } \\
\text { polymerase } \\
+ \\
\text { Chrysophanol D }\end{array}$ & $4^{\text {th }}$ & $\begin{array}{l}\mathrm{VAL}^{30}, \\
\mathrm{VAL}^{6}, \mathrm{ARG}^{9}\end{array}$ & 4306 & 470.90 & -143.02 & $\begin{array}{l}\mathrm{ASP}^{39}, \mathrm{ALA}^{33}, \\
\mathrm{PHE}^{34}, \mathrm{VAL}^{41}\end{array}$ \\
\hline 8. & $\begin{array}{l}\text { RNA } \\
\text { polymerase } \\
+ \\
\text { Eupatorin } \\
\end{array}$ & $4^{\text {th }}$ & $\begin{array}{l}\text { ARD }^{554} \\
\text { ALA }^{684} \\
\text { TYR }^{688} \\
\text { LYS }^{550}\end{array}$ & 5218 & 612.80 & -185.16 & $\begin{array}{l}\text { ILE }^{588}, \text { ASP }^{683} \\
\text { THR }^{686}, \text { SER }^{681}\end{array}$ \\
\hline 9. & $\begin{array}{l}\text { RNA } \\
\text { polymerase } \\
+ \\
\text { Linonene } \\
\end{array}$ & $4^{\text {th }}$ & $\begin{array}{l}\text { ALA }^{687} \\
\text { GLN }^{931} \\
\text { SER }^{758}\end{array}$ & 3542 & 427.10 & -59.56 & $\begin{array}{l}\text { ARG }^{554}, \text { HIS }^{927} \\
\text { SER }^{758}, \text { ASN }^{690}\end{array}$ \\
\hline 10. & $\begin{array}{l}\text { RNA } \\
\text { polymerase } \\
+ \\
\text { Pinene } \\
\end{array}$ & $4^{\text {th }}$ & $\begin{array}{l}\text { HIS }^{132}, \\
\text { CYS }^{21} \\
\text { GLY }^{22} \\
\text { TYR }^{128}\end{array}$ & 3496 & 374.30 & -111.08 & $\begin{array}{l}\mathrm{PRO}^{20}, \mathrm{PHE}^{133}, \\
\mathrm{ASP}^{134}\end{array}$ \\
\hline 11. & $\begin{array}{l}\text { RNA } \\
\text { polymerase } \\
+ \\
\text { Rosmarininc } \\
\text { acid }\end{array}$ & $4^{\text {th }}$ & $\begin{array}{l}\text { GLU }^{810} \\
\text { ASP }^{617}\end{array}$ & 5262 & 611.80 & -84.65 & $\begin{array}{l}\text { SER }^{758}, \text { LYS }^{797}, \\
\text { ASP }^{760}\end{array}$ \\
\hline
\end{tabular}




\begin{tabular}{|c|c|c|c|c|c|c|c|}
\hline 12. & $\begin{array}{l}\text { RNA } \\
\text { polymerase } \\
+ \\
\text { Rutin }\end{array}$ & $1^{\text {st }}$ & $\begin{array}{l}\text { GLN }^{931}, \\
\text { GLY }^{589}, \\
\text { ASP } \\
\text { AL83 } \\
\text { ALA }^{687} \\
\text { THR }^{555} \\
\text { LYS }^{550}\end{array}$ & 5862 & 734.70 & -235.01 & $\begin{array}{l}\text { ALA }^{557}, \text { ILE }^{588} \\
\text { LEU }^{757}\end{array}$ \\
\hline 13 & $\begin{array}{l}\text { RNA } \\
\text { polymerase } \\
+ \text { remdesivir }\end{array}$ & $6^{\text {th }}$ & $\begin{array}{l}\text { SER }^{549}, \\
\text { LYS }^{551}, \\
\text { ARG }^{555}\end{array}$ & 5464 & 663.40 & -279.49 & $\begin{array}{l}\text { SER }^{759}, \text { ASP }^{760}, \\
\text { ASP }\end{array}$ \\
\hline 14. & $\begin{array}{l}\text { RNA } \\
\text { polymerase } \\
+ \\
\text { Hydroxychloroq } \\
\text { uine }\end{array}$ & $1^{\text {st }}$ & $\begin{array}{l}\mathrm{ASP}^{217}, \\
\mathrm{HIS}^{112}, \\
\mathrm{ASN}^{38}, \\
\mathrm{PHE}^{47}\end{array}$ & 4926 & 582.10 & -216.97 & $\begin{array}{l}\text { ASP }^{39}, \text { LYS }^{40} \text {, } \\
\text { PHE }^{44}, \mathrm{ILE}^{113}\end{array}$ \\
\hline 15. & $\begin{array}{l}\text { RNA } \\
\text { polymerase } \\
+ \\
\text { Ivermectin }\end{array}$ & $1^{\text {st }}$ & $\begin{array}{l}\text { THR }^{539} \\
\text { GLN }^{540} \\
\text { MET }^{541} \\
\text { ASN } \\
\text { LEU }^{543} \\
\text { LYS }^{544} \\
\text { TYR }^{45}\end{array}$ & 7092 & 975.80 & -266.44 & $\begin{array}{l}\text { ASN }^{506}, \text { LYS }^{510} \\
\text { GLU }^{559}, \text { VAL }^{560}\end{array}$ \\
\hline
\end{tabular}

C. Results showing interaction of drugs with Helicase

\begin{tabular}{|c|c|c|c|c|c|c|c|}
\hline S. no. & $\begin{array}{l}\text { Receptor + } \\
\text { ligand }\end{array}$ & $\begin{array}{l}\text { Active } \\
\text { pocket } \\
\text { involved }\end{array}$ & $\begin{array}{l}\text { Amino acids } \\
\text { involved in } \\
\text { interaction }\end{array}$ & Score & Area & $\overline{A C E}$ & $\begin{array}{l}\text { Other surrounding } \\
\text { residues }\end{array}$ \\
\hline 1. & $\begin{array}{l}\text { Helicase + } \\
\text { artemisinin }\end{array}$ & $2^{\text {nd }}$ & $\mathrm{ASN}^{557}$ & 3840 & 442.20 & -130.33 & $\begin{array}{l}\text { GLY }^{415}, \text { THR }^{416} \text {, } \\
\text { LEU }^{417}\end{array}$ \\
\hline 2. & $\begin{array}{l}\text { Helicase }+ \\
\text { betaartether }\end{array}$ & $2^{\text {nd }}$ & $\mathrm{ASN}^{557}$ & 4064 & 492.70 & -149.81 & $\begin{array}{l}\text { PRO }^{406}, \text { GLY }^{415} \text {, } \\
\text { THR }^{416}, \text { HIS }^{554}\end{array}$ \\
\hline 3. & $\begin{array}{l}\text { Helicase + } \\
\text { artesunate }\end{array}$ & $2^{\text {nd }}$ & $\mathrm{ASN}^{557}$ & 4614 & 561.80 & -174.04 & $\begin{array}{l}\text { LEU }^{405}, \text { PRO }^{408} \text {, } \\
\text { GLY }^{415}, \text { HIS }^{554}\end{array}$ \\
\hline 4. & $\begin{array}{l}\text { Helicase + } \\
\text { artemether }\end{array}$ & $1^{\text {st }}$ & HIS $^{554}$ & 4002 & 470.20 & -145.50 & $\mathrm{ALA}^{407}, \mathrm{LEU}^{417}$ \\
\hline 5. & $\begin{array}{l}\text { Helicase + } \\
\text { Apigenin }\end{array}$ & $2^{\text {nd }}$ & $\begin{array}{l}\text { SER }^{539}, \\
\text { ARG }^{443} \\
\text { GLN }^{404} \\
\text { LYS }^{288} \\
\text { GLY }^{538}\end{array}$ & 3988 & 470.00 & -99.84 & $\begin{array}{l}\text { HIS }^{290}, \text { GLY }^{287} \text {, } \\
\text { SER }^{289}, \text { SER }^{567} \text {, } \\
\text { THR }^{566}\end{array}$ \\
\hline 6. & $\begin{array}{l}\text { Helicase + } \\
\text { Casticin }\end{array}$ & $1^{\mathrm{st}}$ & $\begin{array}{l}\text { PRO }^{516}, \\
\text { GLY5 }^{15} \\
\text { THR }^{556} \\
\text { HIS }^{584}\end{array}$ & 4400 & 513.90 & -166.74 & $\begin{array}{l}\text { ARG }^{378}, \mathrm{CYS}^{309} \\
\mathrm{MET}^{388}, \mathrm{ASP}^{393} \\
\mathrm{PRO}^{418}\end{array}$ \\
\hline 7. & $\begin{array}{l}\text { Helicase + } \\
\text { Chrysophano } \\
\text { 1 D }\end{array}$ & $2^{\text {nd }}$ & $\begin{array}{l}\mathrm{ARG}^{443}, \\
\mathrm{PRO}^{284} \\
\mathrm{LYS}^{288}\end{array}$ & 3648 & 421.10 & -21.20 & $\begin{array}{l}\text { GLN }^{404}, \mathrm{SER}^{539}, \\
\text { GLN }^{537}, \mathrm{GLY}^{538}\end{array}$ \\
\hline 8. & $\begin{array}{l}\text { Helicase + } \\
\text { Eupatorin }\end{array}$ & $1^{\text {st }}$ & $\begin{array}{l}\text { LYS }^{288} \text {, } \\
\text { PRO }^{284} \text {, } \\
\text { SER }^{289} \text {, } \\
\text { GLU }^{375} \text {, } \\
\text { ALA }^{312} \text {, } \\
\text { ALA }^{313}\end{array}$ & 4440 & 539.40 & -104.88 & $\begin{array}{l}\text { HIS }^{311}, \text { SER }^{310} \\
\text { GLU }^{319}, \text { LYS }^{320}\end{array}$ \\
\hline 9. & $\begin{array}{l}\text { Helicase }+ \\
\text { Linonine }\end{array}$ & $1^{\mathrm{st}}$ & $\begin{array}{l}\mathrm{GLY}^{285}, \\
\mathrm{PRO}^{284}, \\
\mathrm{ARG}^{443}\end{array}$ & 3122 & 355.20 & -63.78 & $\begin{array}{l}\text { LYS }^{288}, \text { GLY }^{287} \text {, } \\
\text { SER }^{289}, \text { THR }^{286}, \\
\text { GLN }^{404}\end{array}$ \\
\hline 10. & $\begin{array}{l}\text { Helicase + } \\
\text { Pinene }\end{array}$ & $1^{\mathrm{st}}$ & $\begin{array}{l}\text { TYR }^{180} \\
\text { LYS }^{139} \\
\text { GLU }^{142}\end{array}$ & 2840 & 314.70 & -36.40 & $\begin{array}{l}\text { LYS }^{146}, \text { GLU }^{143}, \\
\text { THR }^{410}, \text { ASN }^{179}\end{array}$ \\
\hline 11. & $\begin{array}{l}\text { Helicase }+ \\
\text { Rosmarininc } \\
\text { acid }\end{array}$ & $1^{\mathrm{st}}$ & $\begin{array}{l}\text { SER }^{539}, \\
\text { GLN }^{404}, \\
\text { GLY }^{285}, \\
\text { GLN }^{537}, \\
\text { ARG }^{443}\end{array}$ & 4374 & 514.00 & -71.90 & $\begin{array}{l}\mathrm{ARG}^{442}, \mathrm{LYS}^{288} \text {, } \\
\mathrm{SER}^{289}, \mathrm{LYS}^{320}\end{array}$ \\
\hline
\end{tabular}




\begin{tabular}{|c|c|c|c|c|c|c|c|}
\hline 12. & $\begin{array}{l}\text { Helicase + } \\
\text { Rutin }\end{array}$ & $1^{\text {st }}$ & $\begin{array}{l}\text { TYR }^{180}, \\
\text { LYS }^{146} \text {, } \\
\text { GLU }^{143}, \\
\text { THR }^{380}\end{array}$ & 5664 & 606.50 & -41.46 & $\begin{array}{l}\mathrm{ASN}^{176}, \mathrm{CYS}^{309}, \\
\mathrm{ASP}^{383}, \mathrm{TYR}^{382}\end{array}$ \\
\hline 13. & $\begin{array}{l}\text { Helicase + } \\
\text { remdesivir }\end{array}$ & $1^{\text {st }}$ & $\begin{array}{l}\text { LYS }^{139}, \\
\text { SER }^{310} \\
\text { ASN }^{361} \\
\text { THR }^{380}\end{array}$ & 6292 & 774.40 & -139.69 & $\begin{array}{l}\text { ARG }^{178}, \text { CYS }^{309} \\
\text { MET }^{378}, \text { ASP }^{383} \\
\text { PRO }^{408}\end{array}$ \\
\hline 14. & $\begin{array}{l}\text { Helicase }+ \\
\text { Hydroxychlo } \\
\text { roquine }\end{array}$ & $1^{\mathrm{st}}$ & $\begin{array}{l}\text { GLY }^{285}, \\
\text { GLY }^{287} \\
\text { LYS }^{288} \\
\text { SER }^{289}\end{array}$ & 4274 & 492.90 & -45.15 & $\mathrm{GLU}^{319}, \mathrm{LYS}^{320}$ \\
\hline 15. & $\begin{array}{l}\text { Helicase }+ \\
\text { Ivermectin }\end{array}$ & $1^{\mathrm{st}}$ & $\begin{array}{l}\text { CYS }^{309}, \\
\text { SER }^{310} \\
\text { HIS }^{311}, \\
\text { ALA }^{312}\end{array}$ & 6816 & 847.60 & -188.33 & $\begin{array}{l}\mathrm{ASN}^{179}, \mathrm{VAL}^{181}, \\
\mathrm{THR}^{359}, \mathrm{ASN}^{361}\end{array}$ \\
\hline \multicolumn{8}{|c|}{ D. Results showing interaction of drugs with spike (Corona S2) } \\
\hline S. no. & $\begin{array}{l}\text { Receptor + } \\
\text { ligand }\end{array}$ & $\begin{array}{l}\text { Active } \\
\text { pocket } \\
\text { involved }\end{array}$ & $\begin{array}{l}\text { Amino acids } \\
\text { involved in } \\
\text { interaction }\end{array}$ & Score & Area & ACE & $\begin{array}{l}\text { Other surrounding } \\
\text { residues }\end{array}$ \\
\hline 1. & $\begin{array}{l}\text { Spike+ } \\
\text { artemisinin }\end{array}$ & - & $\begin{array}{l}\text { TYR }^{558} \\
\text { CYS }^{584} \\
\text { SER }^{593} \\
\text { ASP }^{600}\end{array}$ & 3958 & 484.70 & -225.03 & $\begin{array}{l}\text { TRP }^{553}, \text { TYR }^{556}, \text { LEU }^{559} \\
\text { CYS }^{594}\end{array}$ \\
\hline 2. & $\begin{array}{l}\text { Spike+ } \\
\text { betaartether }\end{array}$ & - & $\begin{array}{l}\text { TYR }^{547} \\
\text { SER }^{583} \\
\text { CYS }^{584}\end{array}$ & 4182 & 541.4 & -263.36 & TYR $^{550}$, ASP $^{598}$ \\
\hline 3. & $\begin{array}{l}\text { Spike+ } \\
\text { artesunate }\end{array}$ & $2^{\text {nd }}$ & $\begin{array}{l}\text { HIS }^{389} \\
\text { LYS }^{448}\end{array}$ & 4780 & 549.60 & -105.14 & $\begin{array}{l}\text { LYS }^{379}, \text { VAL }^{381,} \text { GLY }^{434} \\
\text { GLN }^{447}\end{array}$ \\
\hline 4. & $\begin{array}{l}\text { Spike+ } \\
\text { artemether }\end{array}$ & - & $\mathrm{TYR}^{556}$ & 4176 & 513.90 & -257.98 & $\begin{array}{l}\text { TYR }^{550}, \text { TRP }^{555}, \text { CYS }^{588} \\
\text { SER }^{593}, \text { CYS }^{594}\end{array}$ \\
\hline 5. & $\begin{array}{l}\text { Spike+ } \\
\text { Apigenin }\end{array}$ & $3^{\text {rd }}$ & $\begin{array}{l}\text { GLN }^{145}, \\
\text { ILE }^{159}, \text { ILE }^{272}\end{array}$ & 4140 & 509.30 & -201.86 & $\mathrm{LYS}^{166}, \mathrm{GLN}^{276}, \mathrm{LEU}^{163}$ \\
\hline 6. & Spike+Casticin & $2^{\text {nd }}$ & $\begin{array}{l}\text { ASN }^{145} \\
\text { GLY }^{159} \\
\text { ILE }^{272}\end{array}$ & 4868 & 584.20 & -275.97 & $\mathrm{TYR}^{166}, \mathrm{ARG}^{76}, \mathrm{LEU}^{163}$ \\
\hline 7. & $\begin{array}{l}\text { Spike+Chrysop } \\
\text { hanol D }\end{array}$ & $2^{\text {nd }}$ & $\begin{array}{l}\text { CYS }^{584} \\
\text { SER }^{583} \\
\text { CYS }^{594} \\
\text { GLU }^{599} \\
\text { TYR }^{550}\end{array}$ & 3980 & 479.30 & -247.15 & $\mathrm{PHE}^{597}, \mathrm{ASP}^{600}, \mathrm{SER}^{593}$ \\
\hline 8. & $\begin{array}{l}\text { Spike+Eupatori } \\
\mathrm{n}\end{array}$ & $2^{\text {nd }}$ & $\begin{array}{l}\text { LEU }^{585}, \\
\text { CYS }^{584} \\
\text { GLU }^{599} \\
\text { ASP } \\
\text { A98 }\end{array}$ & 4538 & 591.40 & -325.16 & $\mathrm{SER}^{593}, \mathrm{SER}^{583}, \mathrm{PHE}^{597}$ \\
\hline 9. & Spike+Linonine & $2^{\text {nd }}$ & $\begin{array}{l}\text { LYS }^{74} \\
\text { GLN }^{115} \\
\text { ILE }^{111}\end{array}$ & 3416 & 389.50 & -142.77 & $\mathrm{ASN}^{296}, \mathrm{ALA}^{299}, \mathrm{TYR}^{348}$ \\
\hline 10. & Spike+ Pinene & $2^{\text {nd }}$ & $\begin{array}{l}\text { TYR }^{556} \\
\text { ASP }^{598} \\
\text { TYR }^{550}\end{array}$ & 3308 & 367.20 & -137.89 & GLU $^{599}$, TRP $^{555}$, LEU $^{559}$ \\
\hline 11. & $\begin{array}{l}\text { Spike+Rosmari } \\
\text { ninc acid }\end{array}$ & $2^{\text {nd }}$ & $\begin{array}{l}\text { LYS }^{596} \\
\text { ASP }^{600} \\
\text { SER }^{583}\end{array}$ & 4930 & 592.10 & -207.23 & $\mathrm{TYR}^{550}, \mathrm{CYS}^{584}, \mathrm{TYR}^{547}$ \\
\hline 12. & Spike+Rutin & $2^{\text {nd }}$ & $\begin{array}{l}\text { SER }^{45}, \\
\text { GLU }^{433}, \\
\text { GLN }^{447}, \\
\text { LYS }^{379}, \\
\text { ILE }^{250}\end{array}$ & 5802 & 665.60 & -138.29 & $\begin{array}{l}\text { TYR }^{388}, \mathrm{GLY}^{249}, \mathrm{SER}^{378}, \\
\mathrm{VAL}^{46}\end{array}$ \\
\hline 13. & $\begin{array}{l}\text { Spike+ } \\
\text { remdesivir }\end{array}$ & $2^{\text {nd }}$ & $\begin{array}{l}\text { GLY }^{249}, \\
\text { ILE }^{250}, \\
\text { LYS }^{379} \\
\text { TYR }^{388}, \\
\text { ARG }^{432} \text {, } \\
\text { GLU }^{433} \text {, } \\
\text { GLN }^{447}\end{array}$ & 6550 & 806.10 & -263.5 & $\begin{array}{l}\mathrm{GLY}^{251}, \mathrm{VAL}^{252}, \mathrm{GLN}^{377} \text {, } \\
\mathrm{SER}^{378}, \mathrm{GLY}^{434}, \mathrm{ASN}^{449}\end{array}$ \\
\hline
\end{tabular}




\begin{tabular}{|c|c|c|c|c|c|c|c|}
\hline 14 & $\begin{array}{l}\text { Spike+ } \\
\text { Hydroxychloroq } \\
\text { uine }\end{array}$ & $2^{\text {nd }}$ & $\begin{array}{l}\text { PHE }^{164}, \\
\text { ALA }^{172}, \\
\text { PHE }^{174}, \\
\text { LYS }^{176}\end{array}$ & 4360 & 477.70 & -178.73 & $\begin{array}{l}\mathrm{PRO}^{204}, \mathrm{LEU}^{206}, \mathrm{THR}^{207}, \\
\mathrm{ASP}^{208}\end{array}$ \\
\hline 145 & $\begin{array}{l}\text { Spike+ } \\
\text { Ivermectin }\end{array}$ & $2^{\text {nd }}$ & $\begin{array}{l}\text { ILE }^{5}, \\
\text { PRO }^{6}, \\
\text { ILE }^{7} \text {, } \\
\text { GLY }^{8}\end{array}$ & 6664 & 869.10 & -256.89 & $\begin{array}{l}\mathrm{ASN}^{20}, \mathrm{SER}^{21}, \mathrm{PRO}^{22}, \\
\mathrm{ARG}^{23}\end{array}$ \\
\hline \multicolumn{8}{|c|}{ E. Results showing interaction of drugs with spike receptor (Glycoprotein) } \\
\hline S. no. & $\begin{array}{l}\text { Receptor }+ \\
\text { ligand }\end{array}$ & $\begin{array}{l}\text { Active } \\
\text { pocket } \\
\text { involved }\end{array}$ & $\begin{array}{l}\text { Amino acids } \\
\text { involved in } \\
\text { interaction }\end{array}$ & Score & Area & ACE & $\begin{array}{l}\text { Other surrounding } \\
\text { residues }\end{array}$ \\
\hline 1. & $\begin{array}{l}\text { Spike receptor + } \\
\text { artemisinin }\end{array}$ & $\begin{array}{l}\text { Rather } \\
\text { than } \\
\text { pocket }\end{array}$ & $\begin{array}{l}\text { SER }^{110} \\
\text { SER }^{181}\end{array}$ & 3806 & 452.20 & -175.57 & $\mathrm{PHE}^{19}, \mathrm{TRP}^{108}, \mathrm{LEU}^{113}$ \\
\hline 2. & $\begin{array}{l}\text { Spike receptor + } \\
\text { betaartether }\end{array}$ & $\begin{array}{l}\text { Rather } \\
\text { than } \\
\text { pocket }\end{array}$ & $\begin{array}{l}\text { TRP }^{108} \\
\text { LEU }^{113}\end{array}$ & 4312 & 518.80 & -181.79 & $\mathrm{SER}^{110}, \mathrm{ASP}^{114}, \mathrm{SER}^{181}$ \\
\hline 3. & $\begin{array}{l}\text { Spike receptor + } \\
\text { artesunate }\end{array}$ & $\begin{array}{l}\text { Rather } \\
\text { than } \\
\text { pocket }\end{array}$ & $\begin{array}{l}\text { SER }^{110}, \\
\text { SER }^{181}\end{array}$ & 4838 & 548.90 & -209.07 & $\mathrm{PHE}^{14}, \mathrm{TRP}^{108}, \mathrm{ASN}^{112}$ \\
\hline 4. & $\begin{array}{l}\text { Spike receptor + } \\
\text { artemether }\end{array}$ & $\begin{array}{l}\text { Rather } \\
\text { than } \\
\text { pocket }\end{array}$ & $\mathrm{TRP}^{108}$ & 4148 & 479.00 & -171.70 & $\mathrm{ASN}^{109}, \mathrm{SER}^{110}, \mathrm{LEU}^{113}$ \\
\hline 5. & $\begin{array}{l}\text { Spike receptor }+ \\
\text { Apigenin }\end{array}$ & $1^{\mathrm{st}}$ & $\begin{array}{l}\text { SER }^{141}, \\
\text { TYR }^{145}\end{array}$ & 3800 & 415.00 & -189.53 & $\mathrm{PRO}^{163}, \mathrm{ASP}^{139}, \mathrm{THR}^{142}$ \\
\hline 6. & $\begin{array}{l}\text { Spike receptor } \\
+ \text { Casticin }\end{array}$ & $1^{\mathrm{st}}$ & $\begin{array}{l}\text { TRP }^{143}, \\
\text { LEU }^{159}\end{array}$ & 4604 & 564.40 & -235.73 & $\mathrm{SER}^{120}, \mathrm{ASP}^{143}, \mathrm{SER}^{192}$ \\
\hline 7. & $\begin{array}{l}\text { Spike receptor } \\
+ \text { +Chrysophanol } \\
\text { D }\end{array}$ & $1^{\mathrm{st}}$ & $\begin{array}{l}\text { PHE }^{14} \\
\text { SER }^{181} \\
\text { ALA }^{44}\end{array}$ & 4042 & 454.40 & -183.23 & $\begin{array}{l}\mathrm{ALA}^{16}, \mathrm{ASN}^{15}, \mathrm{ALA}^{44}, \\
\mathrm{SER}^{110}\end{array}$ \\
\hline 8. & $\begin{array}{l}\text { Spike receptor } \\
\text { +Eupatorin }\end{array}$ & $1^{\mathrm{st}}$ & $\begin{array}{l}\text { THR }^{17}, \\
\text { ASN }^{122}, \\
\text { ASP }^{114}, \\
\text { TYR }^{123}, \\
\text { SER }^{181}\end{array}$ & 4226 & 508.60 & -126.76 & $\mathrm{PHE}^{14}, \mathrm{TRP}^{108}, \mathrm{LEU}^{113}$ \\
\hline 9. & $\begin{array}{l}\text { Spike receptor + } \\
\text { Limonene }\end{array}$ & $1^{\mathrm{st}}$ & $\begin{array}{l}\mathrm{SER}^{18}, \\
\mathrm{PHE}^{14} \\
\mathrm{SER}^{110}\end{array}$ & 3048 & 345.60 & -128.55 & $\mathrm{ASP}^{114}, \mathrm{SER}^{110}, \mathrm{ASN}^{15}$ \\
\hline 10. & $\begin{array}{l}\text { Spike receptor + } \\
\text { Pinene }\end{array}$ & $1^{\text {st }}$ & $\begin{array}{l}\text { LEU }^{113}, \\
\text { TRP } \\
\text { SE8, } \\
\text { SER }\end{array}$ & 2926 & 332.60 & -120.91 & $\mathrm{PHE}^{19}, \mathrm{THR}^{17}, \mathrm{ALA}^{16}$ \\
\hline 11. & $\begin{array}{l}\text { Spike receptor } \\
\text { +Rosmarininc } \\
\text { acid }\end{array}$ & $2^{\text {nd }}$ & $\begin{array}{l}\text { SER }^{18}, \\
\text { ALA }^{44}, \\
\text { TRP }^{108}, \text { PHE } \\
19\end{array}$ & 4604 & 564.00 & -229.61 & $\begin{array}{l}\text { TYR }^{41}, \mathrm{ASN}^{42}, \mathrm{ASP}^{114}, \\
\mathrm{ALA}^{16}\end{array}$ \\
\hline 12. & $\begin{array}{l}\text { Spike receptor } \\
\text { +Rutin }\end{array}$ & $2^{\text {nd }}$ & $\begin{array}{l}\text { TYR }^{41}, \\
\text { ASN }^{42} \\
\text { ASN }^{15}, \\
\text { ASN }^{16}, \\
\text { THR }^{17}, \\
\text { SER }^{181}\end{array}$ & 5392 & 689.50 & -301.22 & $\begin{array}{l}\mathrm{PHE}^{14}, \mathrm{PHE}^{19}, \mathrm{TRP}^{108}, \\
\mathrm{ALA}^{44}\end{array}$ \\
\hline 13. & $\begin{array}{l}\text { Spike receptor + } \\
\text { remdesivir }\end{array}$ & ------ & -------- & 6270 & 783.30 & -398.75 & ------ \\
\hline 14 & $\begin{array}{l}\text { Spike receptor + } \\
\text { hydroxychloroq } \\
\text { uine }\end{array}$ & $2^{\text {nd }}$ & $\begin{array}{l}\mathrm{PHE}^{10}, \\
\mathrm{ASN}^{11}, \\
\mathrm{ALA}^{12}, \\
\mathrm{THR}^{14}, \\
\mathrm{PHE}^{16}\end{array}$ & 4462 & 523.60 & -255.38 & $\begin{array}{l}\mathrm{TYR}^{37}, \mathrm{ASN}^{38}, \mathrm{SER}^{39} \text {, } \\
\mathrm{ALA}^{40}\end{array}$ \\
\hline 15 & $\begin{array}{l}\text { Spike receptor + } \\
\text { Ivermectin }\end{array}$ & $2^{\text {nd }}$ & $\begin{array}{l}\text { PHE }^{10}, \\
\text { ASN }^{11}, \\
\text { ALA }^{12}, \\
\text { THR }^{14}, \\
\text { SER }^{15}, \\
\text { PHE }^{16}\end{array}$ & 6164 & 859.10 & -393.73 & $\begin{array}{l}\mathrm{TYR}^{37}, \mathrm{ASN}^{38}, \mathrm{SER}^{39} \\
\mathrm{ALA}^{40}\end{array}$ \\
\hline
\end{tabular}




\begin{tabular}{|c|c|c|c|c|c|c|c|}
\hline \multicolumn{8}{|c|}{ F. Results showing interaction of drugs with Human ACE2 receptor protein } \\
\hline S. no. & $\begin{array}{l}\text { Receptor + } \\
\text { ligand }\end{array}$ & $\begin{array}{l}\text { Active } \\
\text { pocket } \\
\text { involved }\end{array}$ & $\begin{array}{l}\text { Amino acids } \\
\text { involved in } \\
\text { interaction }\end{array}$ & Score & Area & $\begin{array}{l}\mathrm{ACE} \\
\text { value }\end{array}$ & $\begin{array}{l}\text { Other surrounding } \\
\text { residues }\end{array}$ \\
\hline 1. & $\begin{array}{l}\mathrm{ACE} 2+ \\
\text { artemisinin }\end{array}$ & $1^{\mathrm{st}}$ & $\begin{array}{l}\mathrm{ASN}^{103}, \\
\text { GLN }^{102} \\
\text { TYR }^{196}\end{array}$ & 3548 & 385.10 & -113.74 & $\begin{array}{l}\text { ALA }^{193}, \text { ASN }^{194}, \\
\text { TYR }^{202}\end{array}$ \\
\hline 2. & $\begin{array}{l}\text { ACE2 + } \\
\text { betaartether }\end{array}$ & $1^{\mathrm{st}}$ & $\begin{array}{l}\text { ALA }^{562} \\
\text { TYR }^{521} \\
\text { ASN }^{563}\end{array}$ & 4204 & 452.80 & -152.21 & $\begin{array}{l}\mathrm{VAL}^{209}, \mathrm{TYR}^{207} \text {, } \\
\mathrm{ALA}^{396}, \mathrm{PHE}^{400}\end{array}$ \\
\hline 3. & $\begin{array}{l}\text { ACE2 + } \\
\text { artesunate }\end{array}$ & $1^{\mathrm{st}}$ & $\begin{array}{l}\text { GLN }^{442}, \\
\text { LEU }^{370} \\
\text { PHE }^{438}\end{array}$ & 4628 & 532.30 & -29.42 & $\begin{array}{l}\text { MET }^{366}, \text { LYS }^{441} \text {, } \\
\text { ILE }^{291}\end{array}$ \\
\hline 4. & $\begin{array}{l}\text { ACE2 + } \\
\text { artemether }\end{array}$ & $1^{\mathrm{st}}$ & $\begin{array}{l}\mathrm{HIS}^{195}, \\
\text { TYR }^{196} \\
\text { GLN }^{98}\end{array}$ & 3670 & 414.00 & -100.63 & $\begin{array}{l}\text { TYR }^{202}, \mathrm{GLN}^{101} \\
\mathrm{ASN}^{103}, \mathrm{GLN}^{81}\end{array}$ \\
\hline 5. & $\begin{array}{l}\text { ACE2 + } \\
\text { Casticin }\end{array}$ & $1^{\mathrm{st}}$ & $\begin{array}{l}\mathrm{ASN}^{272}, \\
\mathrm{ILE}^{273}, \\
\mathrm{MET}^{349}, \\
\mathrm{HIS}^{356}\end{array}$ & 4588 & 536.50 & -46.37 & $\begin{array}{l}\text { HIS }^{360}, \text { GLU }^{384}, \\
\text { GLU }^{388}, \text { ALA }^{395}\end{array}$ \\
\hline 6. & $\begin{array}{l}\text { ACE2 + } \\
\text { Chrysophanol D }\end{array}$ & $1^{\mathrm{st}}$ & $\begin{array}{l}\text { GLN }^{81}, \\
\text { GLN }^{102}\end{array}$ & 3652 & 387.00 & -99.55 & $\begin{array}{l}\mathrm{ALA}^{99} \cdot \mathrm{ASN}^{103}, \\
\mathrm{ASN}^{194}\end{array}$ \\
\hline 7. & $\begin{array}{l}\text { ACE2 } \\
+ \text { Eupatorin }\end{array}$ & $1^{\mathrm{st}}$ & $\begin{array}{l}\mathrm{PHE}^{438}, \\
\mathrm{GLN}^{442}, \\
\mathrm{GLU}^{406}\end{array}$ & 4666 & 544.90 & -59.64 & $\begin{array}{l}\mathrm{LYS}^{441}, \mathrm{THR}^{445}, \\
\mathrm{ARG}^{518}\end{array}$ \\
\hline 8. & ACE2 + Pinene & $1^{\mathrm{st}}$ & $\begin{array}{l}\mathrm{LYS}^{441}, \\
\mathrm{MET}^{366}, \\
\mathrm{PHE}^{438}\end{array}$ & 2370 & 338.90 & -84.68 & $\begin{array}{l}\operatorname{LEU}^{370}, \text { ALA }^{413}, \\
\operatorname{GLN}^{442}\end{array}$ \\
\hline 9. & $\begin{array}{l}\text { ACE2 + } \\
\text { Rosmarinic acid }\end{array}$ & $1^{\mathrm{st}}$ & $\begin{array}{l}\text { HIS }^{374}, \\
\text { ILE }^{291}, \\
\text { ASN }^{290}, \\
\text { SER }^{409}\end{array}$ & 4406 & 494.20 & -113.63 & $\begin{array}{l}\text { LEU }^{370}, \text { ALA }^{413} \text {, } \\
\text { MET }^{366}, \text { LYS }^{441}\end{array}$ \\
\hline 10. & $\begin{array}{l}\text { ACE2 + } \\
\text { Apigenin }\end{array}$ & $1^{\mathrm{st}}$ & $\begin{array}{l}\text { TYR }^{207} \\
\text { TYR }^{521} \\
\text { PHE }^{400} \\
\text { ASN }^{397} \\
\text { VAL }^{561}\end{array}$ & 3796 & 418.60 & -160.86 & $\begin{array}{l}\text { VAL }^{561}, \text { PHE }^{525}, \\
\text { VAL }^{559}, \text { ALA }^{562}\end{array}$ \\
\hline 11. & $\begin{array}{l}\text { ACE2 + } \\
\text { Linonene }\end{array}$ & $1^{\mathrm{st}}$ & $\begin{array}{l}\mathrm{ILE}^{291}, \\
\mathrm{LEU}^{370} \\
\mathrm{PHE}^{438}\end{array}$ & 2934 & 346.10 & -59.89 & $\begin{array}{l}\mathrm{GLN}^{442}, \mathrm{ASN}^{290}, \\
\mathrm{ALA}^{413}\end{array}$ \\
\hline 12. & ACE2 + Rutin & $1^{\mathrm{st}}$ & $\begin{array}{l}\text { TYR }^{207}, \\
\text { ALA }^{562} \\
\text { VAL }^{561} \\
\text { ASN }^{563} \\
\text { ARG }^{560} \\
\text { LEU }^{564}\end{array}$ & 5348 & 647.70 & -388.24 & $\begin{array}{l}\text { TYR }^{217}, \text { VAL }^{559}, \\
\text { GLN }^{524}\end{array}$ \\
\hline 13. & $\begin{array}{l}\text { ACE2 + } \\
\text { Remdesivir }\end{array}$ & $1^{\mathrm{st}}$ & $\begin{array}{l}\text { TYR }^{184} \\
\text { GLY }^{187} \\
\text { ASP }^{188} \\
\text { TYR }^{189} \\
\text { GLU }^{190}\end{array}$ & 6564 & 812.60 & -318.63 & $\begin{array}{l}\text { LEU }^{373}, \text { LEU }^{374}, \\
\text { ARG }^{375}, \text { ASN }^{376}, \\
\text { GLY }^{377}\end{array}$ \\
\hline 14 & $\begin{array}{l}\text { ACE2 + } \\
\text { Hydroxychloroq } \\
\text { uine }\end{array}$ & $1^{\mathrm{st}}$ & $\begin{array}{l}\text { TYR }^{189}, \\
\text { VAL }^{191}, \\
\text { TYR }^{199}\end{array}$ & 4134 & 466.80 & -208.38 & $\begin{array}{l}\mathrm{HIS}^{360}, \mathrm{ALA}^{379}, \\
\mathrm{MET}^{380}\end{array}$ \\
\hline 15 & $\begin{array}{l}\text { ACE2 + } \\
\text { Ivermectin }\end{array}$ & $1^{\mathrm{st}}$ & $\begin{array}{l}\text { LEU }^{77}, \\
\text { GLU }^{80} \text {, } \\
\text { ALA }^{81} \text {, } \\
\text { GLU }^{84}\end{array}$ & 6768 & 770.80 & -245.70 & $\begin{array}{l}\text { TYR }^{184}, \text { GLY }^{188} \text {, } \\
\text { ASP }^{189}, \text { GLU }^{190}\end{array}$ \\
\hline
\end{tabular}

In the present study, we first dissected the genome into 5 parts: (1) whole CDS (ORF1a), (2) helicase, (3) RNA polymerase, (4) spike protein, and (5) glycoprotein portion of SARS 2019-nCov, and analyzed the interaction of some major bioactive compounds of $A$. апnиa along with antimalarial compound artemisinin and its derivatives with each subset of ORFs (Fig. 1). The ORF 1a (nucleotide 266 to 13,468$)$ is responsible for coding papain-like proteinase (PLpro) that cleaves $\mathrm{N}$-terminus of the replicase polyprotein to release Nsp1, Nsp2 and Nsp3 for correcting virus replication and 3 C-like main protease (3CLpro) that facilitates the maturation of Nsps, which is needed for the virulent life cycle of the coronavirus (Wang et al., 2020). Both of them are attractive targets for anti-coronavirus drug 
development. Another ORF $1 \mathrm{~b}$ includes expression of RNA-dependent RNA polymerase ( $R d R p)$ (starting from nucleotide13,442 to 16,236 also known as Nsp12, a highly conserved protein of coronavirus replication/transcription complex and Helicase (Nsp13), a multi-functional protein, include $\mathrm{N}$-terminal metal-binding domain and helicase domain which is a necessary component for the replication of coronavirus (Kirchdoerfer and Ward, 2019). Besides this, in our study, another target that has been selected here is a virus structural spike protein (nucleotide 21,563 to 25,384) that interacts with the host cell receptors and causing virus invasion into the host. Spike structural integrity and its activated cleavage play a crucial deciding role in virulence capacity.

\section{Structural Modelling and Validation}

Sequence analysis and model validation through MSA and phylogenetic analysis revealed the close homologues of SARS-nCoV (Fig. 3). All the five modeled protein qualities were validated using RAMAPAGE and PROCHECK analysis which confirm the superiority of model proteins with $98.0 \%, 92.2 \%, 95.3 \%, 79.1 \%$, and $94.5 \%$ residues were present in favoured region of Corona peptidase, RNA dependent RNA polymerase (RdRp), helicase, spike, and glycoprotein respectively (Fig. 10; Table 3). Further, active site prediction and molecular docking analysis revealed the actual active sites of the receptor proteins which is involved in the interaction with ligands by covalent or non-covalent interactions (Subissi et al., 2014). The result of Metapocket 2.0 server identified the pockets sharing same amino acid residues along with interacting residues which are asPocket $1^{\text {st }}$ - HIS ${ }^{2352}, \mathrm{MET}^{2360}, \mathrm{LEU}^{2361}, \mathrm{HIS}^{2352}, \mathrm{ASN}^{2453}$, $\mathrm{GLY}^{2454}, \mathrm{CYS}^{2456}, \mathrm{HIS}^{2474}, \mathrm{HIS}^{2475}, \mathrm{MET}^{2476}$, and GLU ${ }^{2477}$ for the whole peptidase, Pocket $4^{\text {th }}-\mathrm{PHE}^{206}, \mathrm{GLY}^{207}$, $\mathrm{PHE}^{209}, \mathrm{ASP}^{208}, \mathrm{ILE}^{188}, \mathrm{ALA}^{186}, \mathrm{GLN}^{211}, \mathrm{PHE}^{179}, \mathrm{ALA}^{182}$, and $\mathrm{MET}^{183}$, and Pocket $6^{\text {th }}-\mathrm{LEU}^{257}, \mathrm{LEU}^{258}, \mathrm{LYS}^{259}$, $\mathrm{TYR}^{260}, \mathrm{LEU}^{316}, \mathrm{THR}^{331}, \mathrm{GLY}^{332}, \mathrm{VAL}^{340}, \mathrm{VAL}^{341}, \mathrm{HIS}^{342}$, $\mathrm{SER}^{318}, \mathrm{TYR}^{333}, \mathrm{VAL}^{317}, \mathrm{PRO}^{315}, \mathrm{SER}^{312}, \mathrm{THR}^{311}, \mathrm{ASP}^{256}$, $\mathrm{PHE}^{313}$, GLY ${ }^{314}$, and $\mathrm{PRO}^{310}$ for RNA dependent RNA polymerase. Besides these, 611TPHLMGWDYPKCDRAM-626 and 753FSMMILSDDAVVCFN-767 are also involved in the interaction (Gao et al., 2020). From helicase receptor, Pocket $1^{\text {st }}-\mathrm{LYS}^{139}, \mathrm{SER}^{310}, \mathrm{ASN}^{361}, \mathrm{THR}^{380}$, and $\mathrm{HIS}^{554}$ and pocket $2^{\text {nd }}-\mathrm{ASN}^{557}$ were involved in the interaction. Further, active site in spike protein, sharing interaction with the ligands were found as Pocket $2^{\text {nd }}-G_{L Y}^{249}, \operatorname{ILE}^{250}$, $\mathrm{LYS}^{379}$, TYR ${ }^{388}, \mathrm{HIS}^{389}, \mathrm{ARG}^{432}, \mathrm{GLU}^{433}, \mathrm{GLN}^{447}$, andLYS ${ }^{448}$. However, analysis of active sites of glycoprotein domain showed no pockets were involved in the interaction, as all the interacting residues were found to be other than the pockets (Table 2).

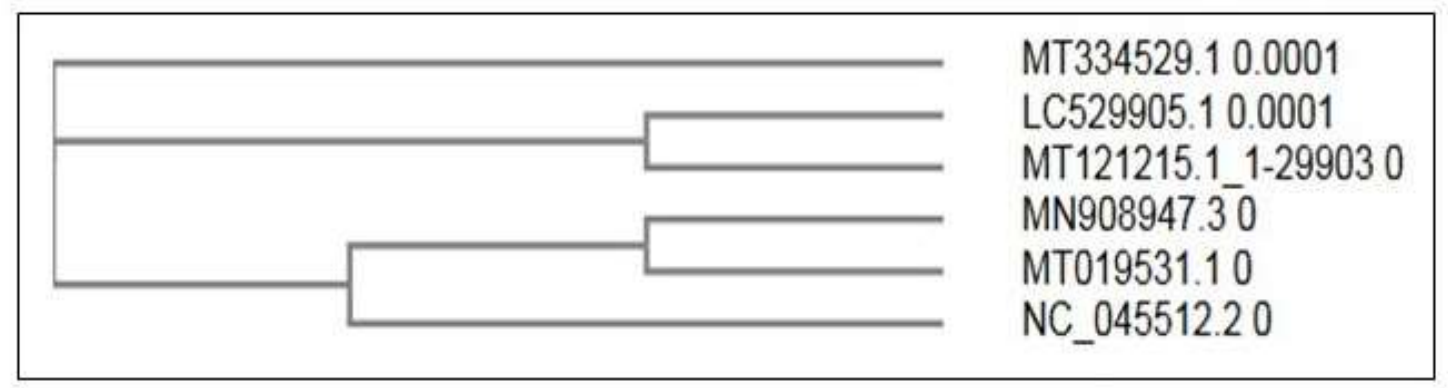

Fig. 3: Phylogenetic tree depicting the closer homologues of SARS-CoV-2

Table 3: Quantitative and qualitative assessment of modelled proteins

\begin{tabular}{|l|l|l|l|l|l|l|}
\hline \multirow{2}{*}{ S. no. } & $\begin{array}{l}\text { Type of protein } \\
\text { studied }\end{array}$ & \multicolumn{2}{|l|}{$\begin{array}{l}\text { Result of Ramapage quality assessement } \\
\text { (No. of amino acid residues in)- }\end{array}$} & $\begin{array}{l}\text { Results } \\
\text { Prosa server }\end{array}$ & $\begin{array}{l}\text { GRA } \\
\text { Score }\end{array}$ \\
\cline { 2 - 7 } & $\begin{array}{l}\text { favoured } \\
\text { region } \\
\text { region }\end{array}$ & $\begin{array}{l}\text { outlier } \\
\text { region }\end{array}$ & Z-score & \\
\hline 1. & $\begin{array}{l}\text { Corona peptidase } \\
\text { (nsp3, 4, and 6) }\end{array}$ & $98.0 \%$ & $1.3 \%$ & $0.7 \%$ & -6.61 & 0.024 \\
\hline 2. & $\begin{array}{l}\text { Corona RNA } \\
\text { dependent RNA } \\
\text { polymerase (nsp12) }\end{array}$ & $92.2 \%$ & $5.8 \%$ & $1.9 \%$ & -11.06 & -0.135 \\
\hline 3. & $\begin{array}{l}\text { Corona helicase } \\
\text { protein }\end{array}$ & $95.3 \%$ & $3.8 \%$ & $0.8 \%$ & -9.6 & -0.004 \\
\hline 4. & $\begin{array}{l}\text { Corona spike } \\
\text { protein }\end{array}$ & $79.1 \%$ & $11.7 \%$ & $9.2 \%$ & -6.7 & -0.182 \\
\hline 5. & $\begin{array}{l}\text { Corona } \\
\text { glycoprotein }\end{array}$ & $94.5 \%$ & $4.4 \%$ & $1.1 \%$ & -5.39 & 0.036 \\
\hline
\end{tabular}




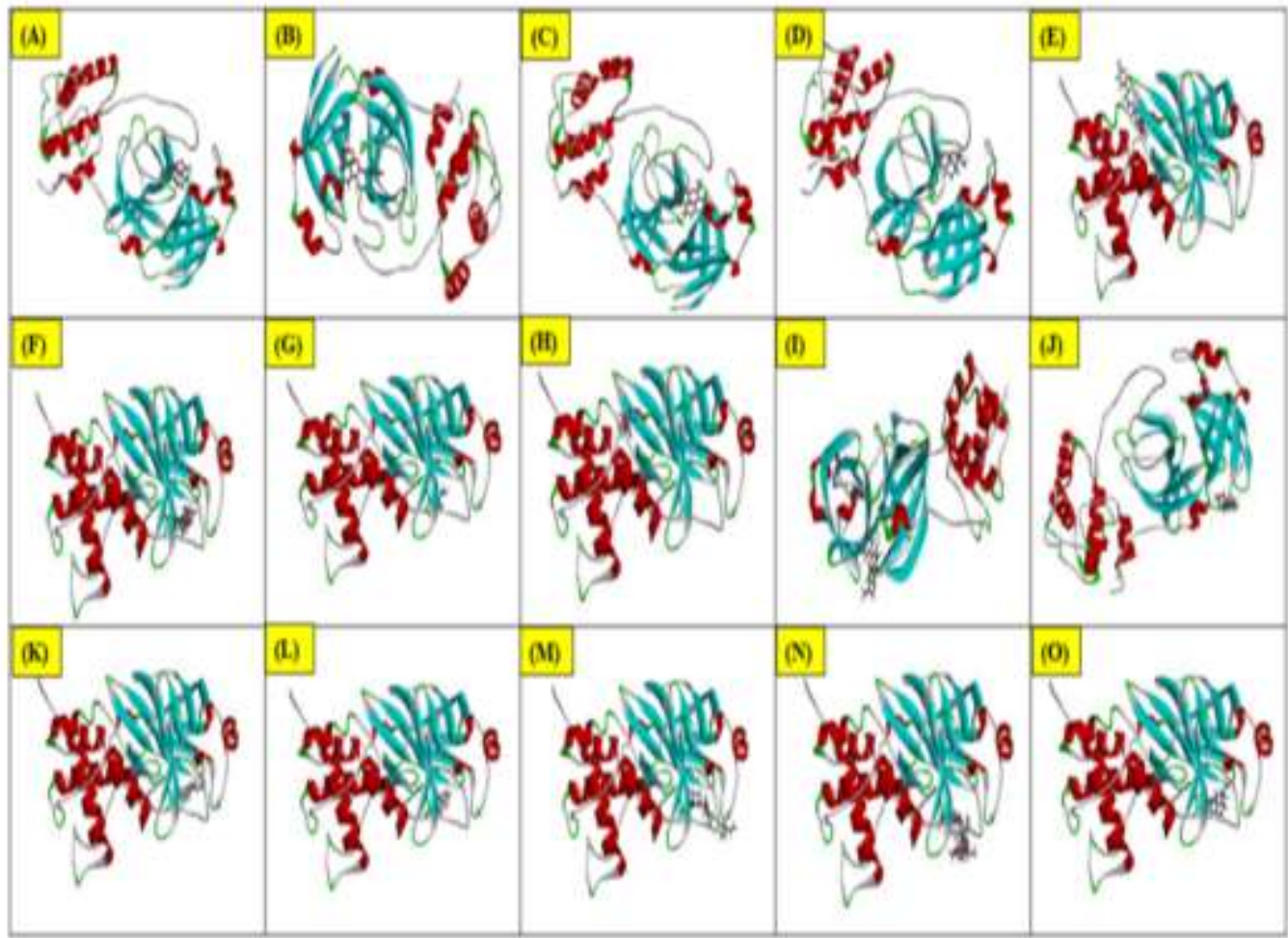

Fig. 4: Patchdock analysis showing the interactions of ligands to the protease residue of SARS$\mathrm{CoV}-2$. A-O are the interactions of protease with Artemisinin, Betaartether, Artesunate, Artemether, Rosmarininc acid, Rutin, Linonene, Pienen, Eupatorin, Chrysophanol D, Casticin, Apigenin, Remdesivir, Ivermectin, Hydroxychloroquine respectively. Remdesivir, Ivermectin and Hydroxychloroquine are the control ligand.

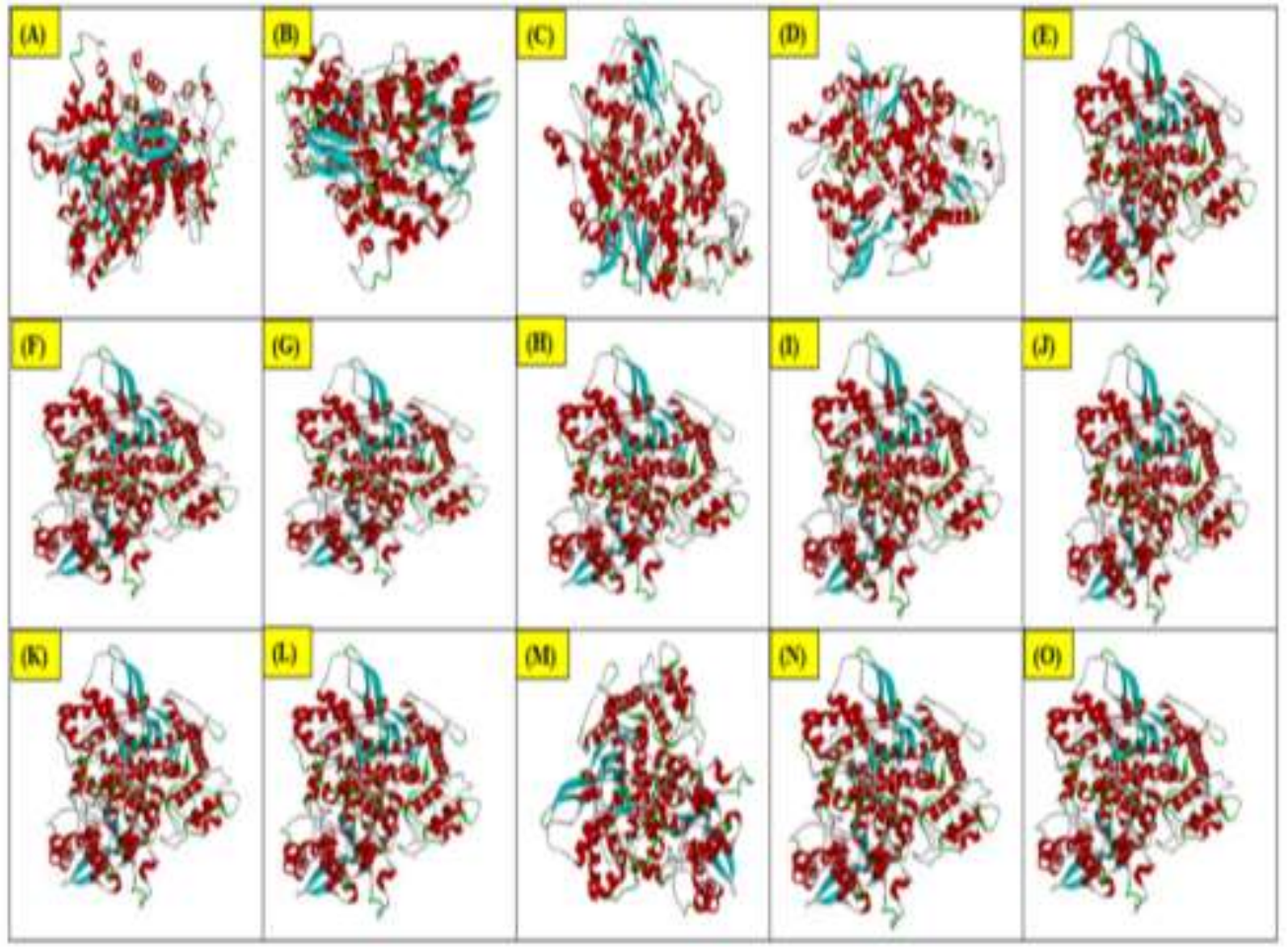

Fig. 5: Patchdock analysis showing the interactions of ligands to the RNA Polymerase (Whole nsp12) residue of SARS-CoV-2. A-O are the interactions of RNA Polymerase with Artemisinin, Betaartether, Artesunate, Artemether, Rosmarininc acid, Rutin, Linonene, Pienen, Eupatorin, Chrysophanol D, Casticin, Apigenin, Remdesivir, Ivermectin and Hydroxychloroquine respectively. Remdesivir, Ivermectin and Hydroxychloroquine are the control ligand. 


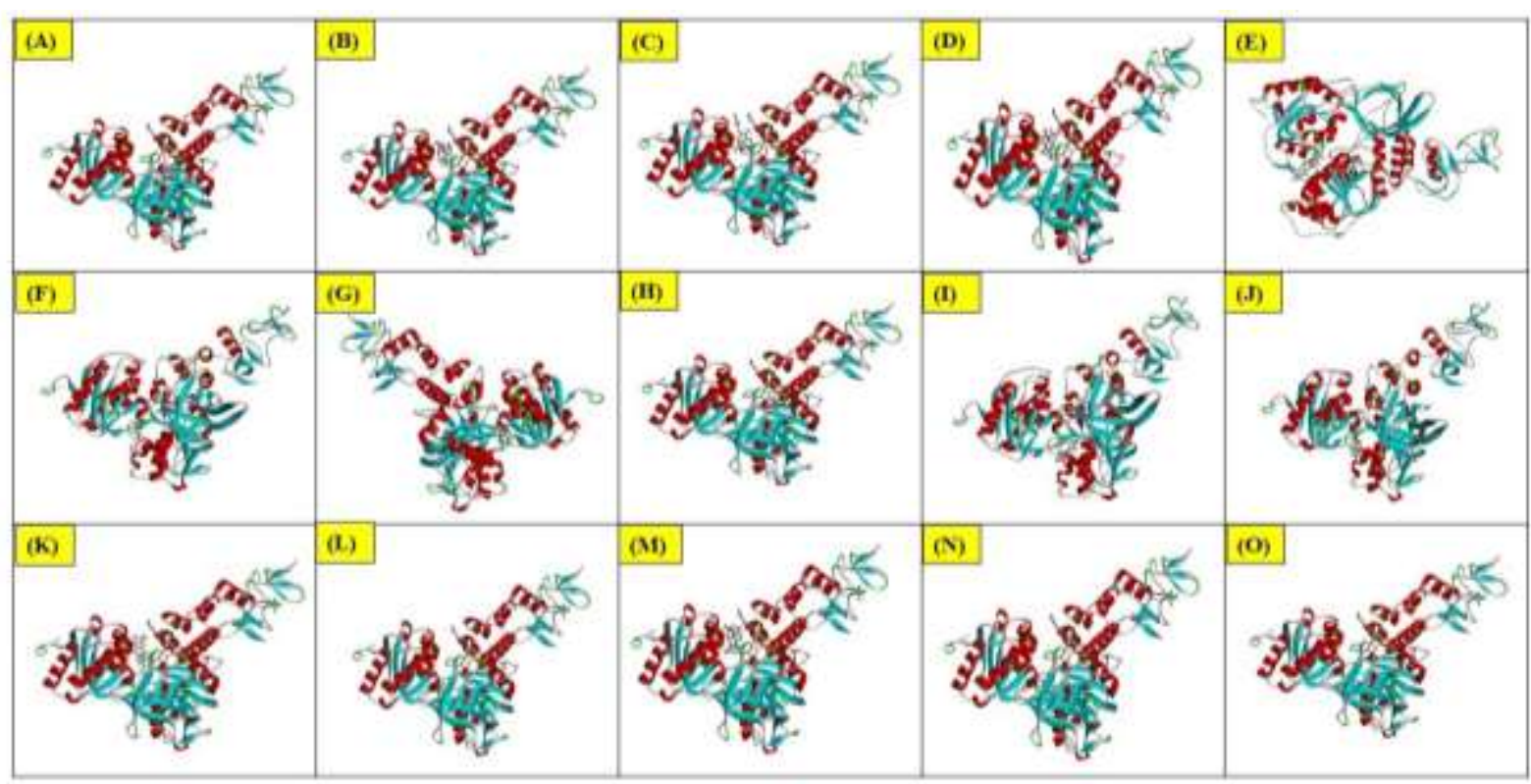

Fig. 6: Patchdock analysis showing the interactions of ligands to the Helicase residue of SARS-CoV-2. A-O are the interactions of Helicase residue with Artemisinin, Betaartether, Artesunate, Artemether, Rosmarininc acid, Rutin, Linonene, Pienen, Eupatorin, Chrysophanol D, Casticin, Apigenin, Remdesivir, Ivermectin and Hydroxychloroquine respectively. Remdesivir, Ivermectin and Hydroxychloroquine are the control ligand.

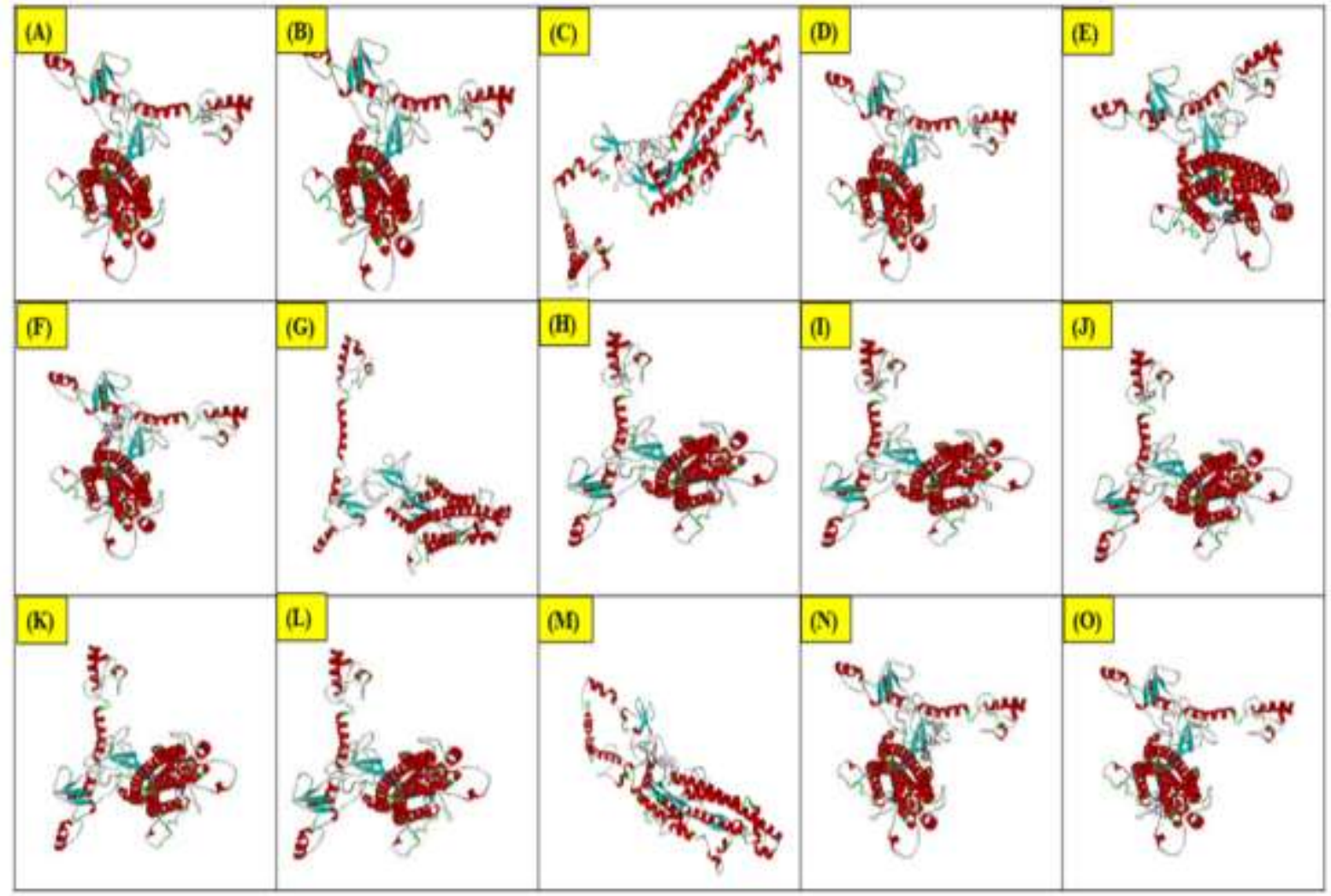

Fig. 7: Patchdock analysis showing the interactions of ligands to the Spike residue of SARS-CoV-2. A-O are the interactions are the interactions of Spike residue with Artemisinin, Betaartether, Artesunate, Artemether, Rosmarininc acid, Rutin, Linonene, Pienen, Eupatorin, Chrysophanol D, Casticin, Apigenin, Remdesivir, Ivermectin and Hydroxychloroquine respectively. Remdesivir, Ivermectin and Hydroxychloroquine are the control ligand. 


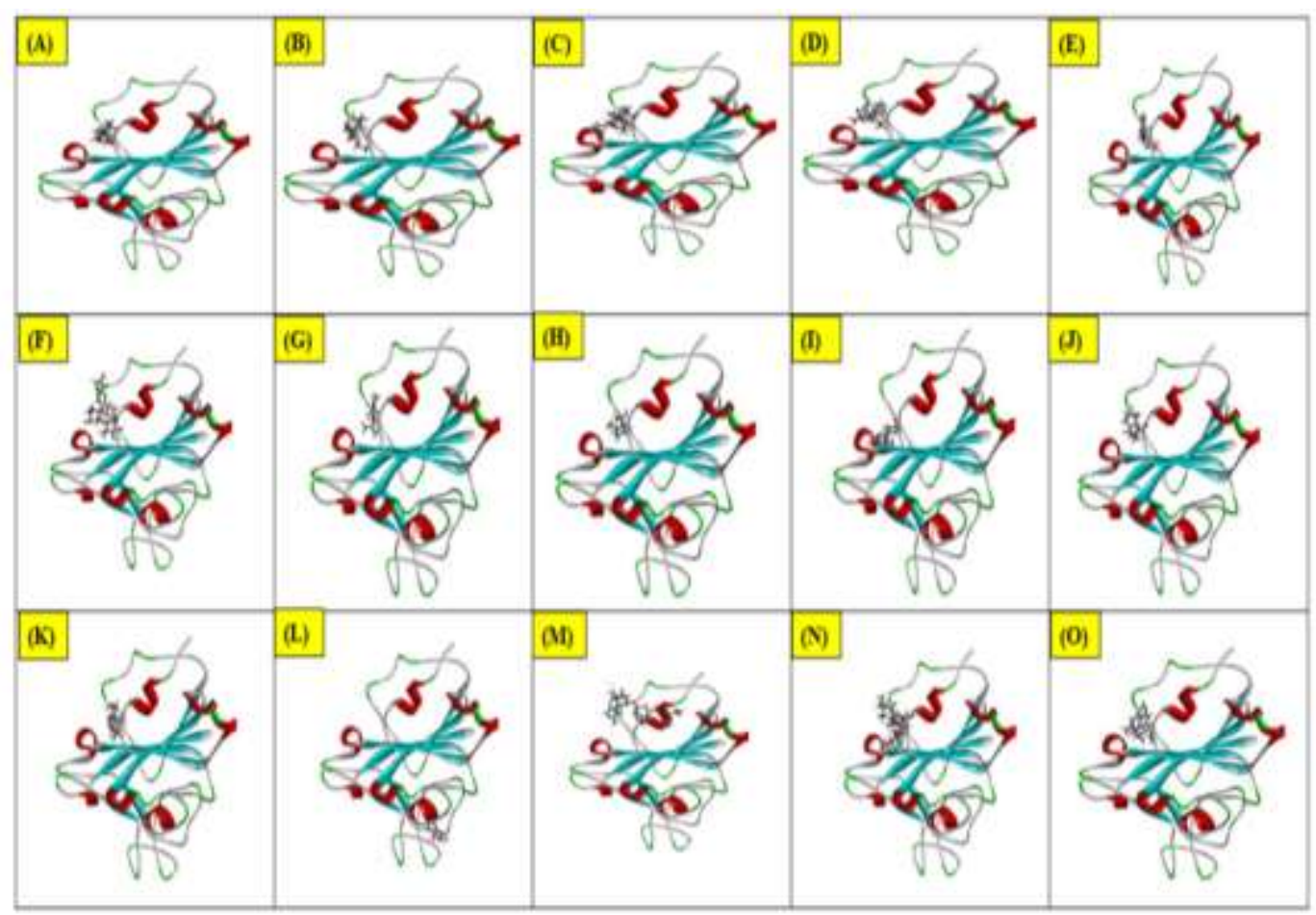

Fig. 8: Patchdock analysis showing the interactions of ligands to the Glycocapsid residue of SARS-CoV-2. A-O are the interactions of Glycocapsid with Artemisinin, Betaartether, Artesunate, Artemether, Rosmarininc acid, Rutin, Linonene, Pienen, Eupatorin, Chrysophanol D, Casticin, Apigenin, Remdesivir, Ivermectin and Hydroxychloroquine respectively. Remdesivir, Ivermectin and Hydroxychloroquine are the control ligand.

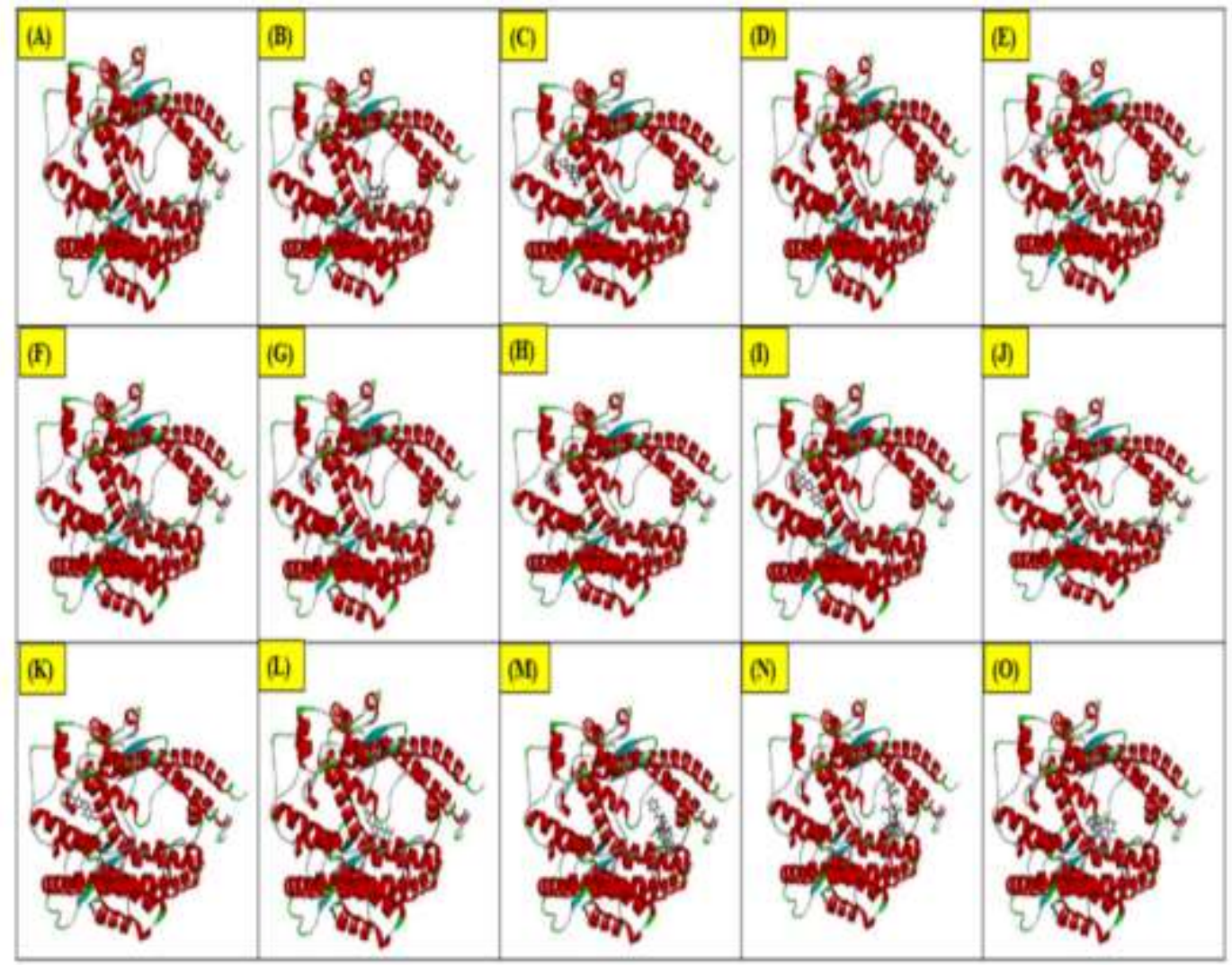

Fig. 9: Patchdock analysis showing the interactions of ligands to the Human ACE 2 protein. A-O are the interactions of Human ACE 2 with Artemisinin, Betaartether, Artesunate, Artemether, Rosmarininc acid, Rutin, Linonene, Pienen, Eupatorin, Chrysophanol D, Casticin, Apigenin, Remdesivir, Ivermectin and Hydroxychloroquine respectively. Remdesivir, Ivermectin and Hydroxychloroquine are the control ligand. 


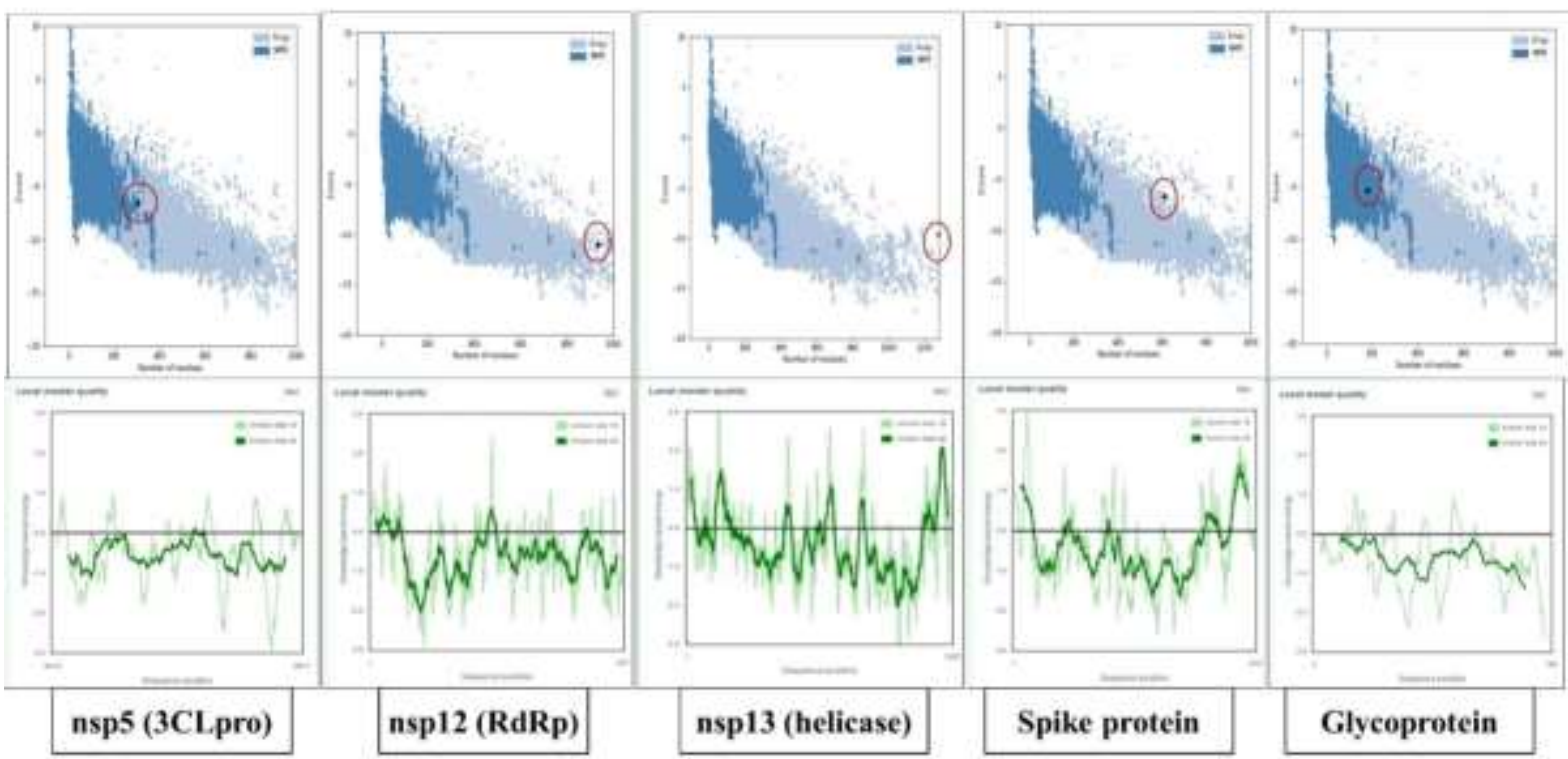

Fig. 10: Quantitative and qualitative analysis of (1) whole CDS (ORF1a), (2) helicase, (3) RNA polymerase, (4) spike protein, and (5) glycoprotein portion of SARS 2019-nCov.

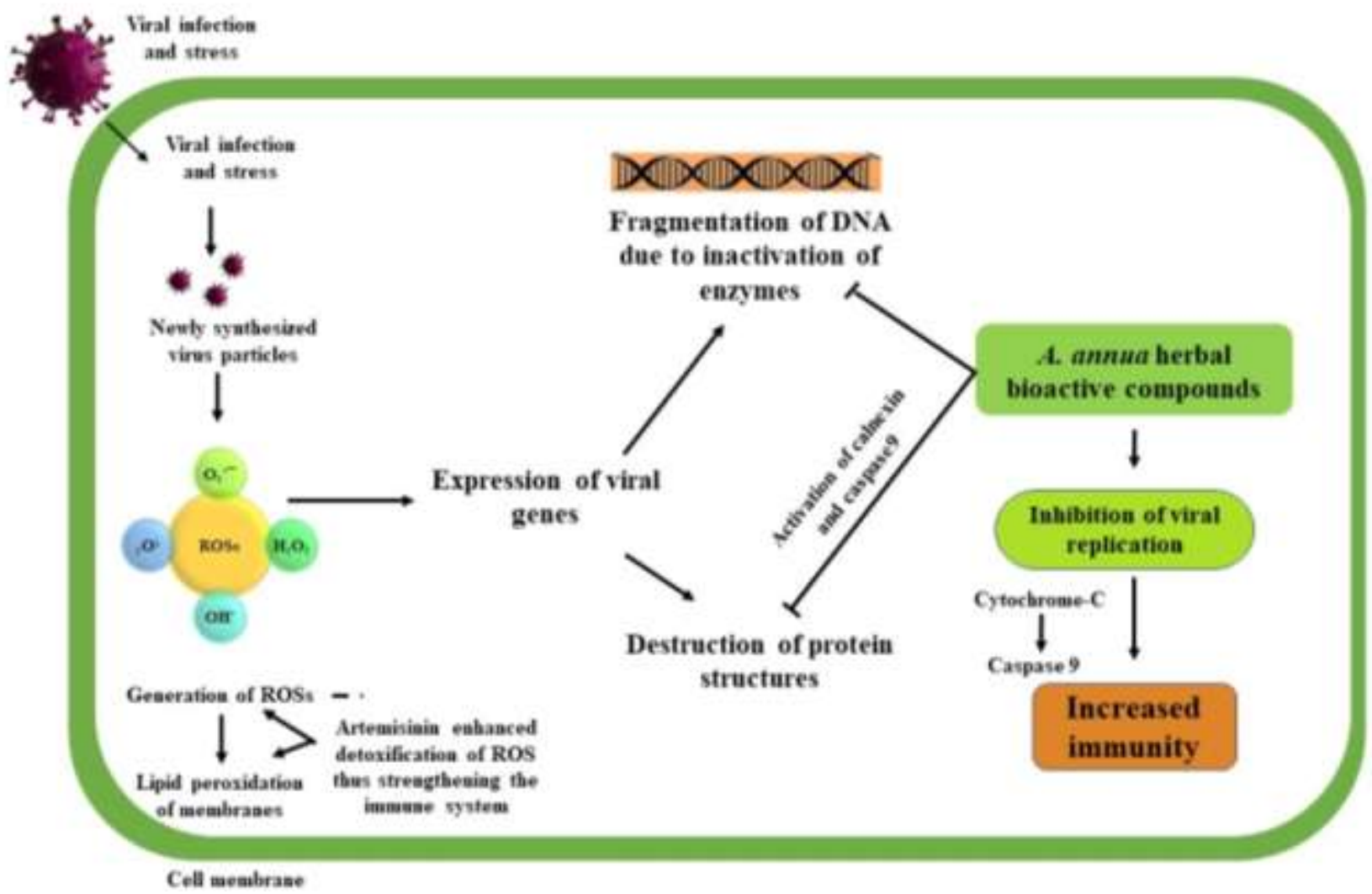

Fig. 11: Schematic representation of different processes that are stimulated upon viral infection and countermeasures adopted by cells to eliminate the threat and simultaneously boosting immunity with in the body.

\section{Molecular Docking and Interaction}

After the analysis of active sites, molecular docking of receptors and ligands was done by Patchdock server, and results with the highest score were analyzed further. All the interacting residues, area, score, and ACE values of the interactions are compiled in Table 2A-2E, which shows that majority of amino acid residues taking part in interaction with ligands, were common to those within binding sites as depicted by Metapocket. The docking results indicated that remdesvir, hydroxychloroquine and ivermectin interacted strongly with protease ORF1a by GLY, SER and LEU (binding score -263.46 - 422.56) residues where as HIS, MET and TYR residues were also involved in stabilizing the interaction by covalently interacting with the former 
residues (Table 2A; Fig. 6). These interacting amino acids were also found to be common in artemisinin, beta-arteether and casticin suggesting the strong conservation of these amino acid residues (binding score -176.24 to -256.33 ). Similarly, docking results of all the ligands with RNA dependent RNA polymerase (RdRp) is shown in Fig. 5. The RdRp was found to be in interaction with HCQ and ivermectin with conserved ASN, LYS, TYR and PHE residues with the docking score of -216.9 to -266.44 which indicate a strong bnding of these componds to the receptor complex (Table 2B; Fig. 5). Other phytocomponds which also showed interaction with RdRp with similar core amino acid residues along with other residues (VAL and ASP) were artmesisnin, artesunate, eupatorin and rosamrininc acid (Fig. 2B). It is already reported by Gao et. al. that RdRp make a hydrogen bond with remdesivir and other phytocompounds by THR, SER, and ASP which is in accordance with the results of the present study.

The control ligands viz., remdesvir, HCQ and ivermectin interacted with helicase receptor with conserved GLY, SER, LYS and ASN amino acid residues along with other supporting amino acid residues with the docked score of 45.15 to -188.33 indicating strong interaction with the helicase receptor (Table 2C; Fig. 6). On the contrary, the phytocompounds that were in interaction with helicase domain with similar conserved amino acid residues were artemisinin, apigenin, chrysophanol D, eupatorin and pinene with the docked score of -21.2 to -130.3 thus validating the effectiveness of these residues (Imbert et al., 2006).Molecular interaction of spike protein with control ligands reveals strong interaction with control ligands viz., remdesvir, HCQ and ivermectin via PHE, PRO, ILE and LYS amino acid residues with docking score of -178.7 to 263.5 and these residues were also responsible for the interaction with artesunate, apigenin and limonene with spike receptor with docking score of -105.1 to -201.1 (Table 2D; Fig. 7). Furthermore, remdesvir, HCQ and ivermectin also exhibhited good score and most negative ACE values of docked complex showing PHE, ASN, ALA and THR were the core amino acid residues involved in the interaction (Table 2E; Fig. 8). Among phytocompounds that showed interaction with glycoprotein with similar amino acid residues were chrysophanol $\mathrm{D}$, eupatorin and rutin whereas artemisinin and its derivatives showed interaction with SER, TRP and LEU residues which may be due to the point mutation that have alter the binding of these compounds thus affecting their ability to bind with SARSnCoV inhibitors. Furthermore, human ACE-2 protein interated with the HCQ via TYR and VAL residues whereas ivermectin exbhited interaction with ACE-2 protein via GLU, ALA and LEU residues (Table 2F; Fig. 9). On the contrary, remdesviralong with artemisinin, beta-artether and rosmarinic acid interacted with core amino acid residues viz., TYR, GLY, ASP and ASN (Table 2F). Several independent research groups investigated that
SARS-nCoV also utilizes ACE-2 as a cellular entry receptor in humans. The ACE- 2 receptor is a vital element for regulating processes such as wound healing inflammation and blood pressure by the renin-angiotensinaldosterone system (RAAS) pathway (Imbert et al., 2006). It can be hypothesized that treating patients with ACE inhibitor $\left(\mathrm{ACE}_{\mathrm{i}}\right)$ can reduce the Angiotensin $\mathrm{i}_{2}$ accumulation which is the substrate for ACE-2 by preventing ACE mediated cleavage of Angiotensin ${ }_{1 \text { to }}$ thereby having potential to negatively regulate RAAS. The ACE- 2 have shown a protective function in the cardiovascular system and other organs also. The modulation of RAAS activation through the ACE2/Ang 1-7 pathway should be considered for treatment of COVID-19 disease. The bioactive compounds artemisinin, $\beta$ arteether, rosmarnic acid, rutin and apigenin have shown ACEi potential in this study.

Overall, the present study identified potential, non-toxic natural bioactive compounds that showed strong interaction with helicase domain, RdRp receptor and spike protein receptor of SARS-nCoV (Table 2 and Fig. S2-S7). Among these screened phytochemicals, artemisnin, beta-artether, artesunate, and eupatorin exhibited highest binding affinity with docking score ranging from -21.2 to -130.3 as well as significant binding with the spike protein and RdRp receptor proteins (Table 2A-2F, Fig. 4-9). Artimisinin and its derivatives has been proven superior to quinine and other malarial drugs in endemic regions of malaria and the drug is currently recommended as the first-line treatment for severe malaria by the World Health Organization (WHO, 2020; Zhou et al., 2005) which has also been reported in Chinese medical reportire.In addition, eupatorine is a natural flavonoid and has been reported for its anticancerous and anti-inflammatory properties (Razak et al., 2019; Laavola et al., 2012).Eupatorin has the ability to modulate immune system and hence, was probably found to have strong affinity with the viral proteins thus strengthening its potential as a candidate drug against SARS-nCoV.). Another bioactive compound apigenin have potential to activate $\mathrm{B}$ cells and inactivate nuclear factor kappa-light-chain-enhancer in human cell culture. It decreases the expression of adhesion molecules, which is a defensive strategy against oxidative stress. It also promotes different anti-inflammatory pathways, have capabilitiy to reduce COX-2 activity along with preventive role in the IKB degradation and nuclear translocation of the NF- $\kappa B$. Our screened phytocompounds specially artemisnin, betaartether, artesunate, and eupatorin showed strong binding energies, docking scores and close interaction with core amino acid residues equivalently to remdesvir, HCQ and ivermectin against SARS-nCOV.

Recently, the researcher tested in vitro antiviral activities of $A$. annua whole plants herbal preparations against SARS-nCoV for prophylaxis and treatment of COVID-19. In China, most of the infected patient receiving traditional 
Chinese medicine for treatment of COVID-19 and few evidences have already demonstrated that the herbal preparation of A. апnиa is effective against SARS-nCoV infectious diseases (Yang et al., 2020). Our in-silico results of the present study suggested that these naturally derived phytochemicals of A. annua can be useful candidates for SARS-nCoV drug therapy (Fig. 2 and Fig. 11). Though properties of $A$. annua bioactive compounds are appreciable in-silico studies, the in-vitro and clinical trials dealing with SARS-nCoV should be considered for further studies.

\section{Conclusion}

Artemisinin and its derivatives are known as potential antimalarial agents due to their high efficiency and lower toxicity. Besides its excellent antimalarial activity, artemisinin and its conjugates also possess immunomodulatory functions and are experimentally used to treat viral and autoimmune diseases. We summarized here the recent possibilities of artemisinin and /or itsconjugatives in treating COVID-19 and other inflammatory disorders. We conclude that artemisinin along with its derivatives showed good interaction with SARS$\mathrm{nCoV}$ and have potential to perform as good antiviral agent primarily by down regulating $\mathrm{T} \& \mathrm{~B}$ cell activation, inhibiting antibody production, and expanding the function of regulatory $\mathrm{T}$ cells.In the present study, molecular docking analysis revealed that all the ligands become activated and exert immunoregulatory response after possible interaction with protease, helicase, RDRP, spike and glycoprotein domain by His, Met, Glu, Leu, Val, Asp, Phe, Tyr, Val, Gly, Ile, Lys, Arg, Glu, and Gln residues as compared to control remdesvir, HCQ and ivermectin where the interacting domains were also Val, Asp, Phe, Tyr, Val, Gly, Ile, Lys, Arg, Glu His, Met and Glu suggesting strong condensed nature of core amino acid residues involved in triggering effective anti-inflammatory and immunoregulatory mechanism of action. We believe that, as anti-inflammatory/ antiviral agents, artemisinin and its derivatives are much more potent capable of acting on various frontiers within the viral cascade, thereby reducing virulence activity with discrimination for stimulated $\mathrm{T}$ cells, to produce a synergistic effective treatment on disease activity. Thus, this artemisinin, its derivatives and various other bioactive components present in A. annua leaf may be promising candidates for the treatment of inflammation, immunomodulatory disorders and other symptoms induced by a viral infection in COVID-19.

\section{Authors' Contribution}

All authors have contributed equally to the manuscript.

\section{Conflict of Interest}

The authors declare that there is no conflict of interest with present publication

\section{Acknowledgement}

The authors are thankful to DST (Department of Science and Technology), and DBT-ISLS facility, BHU, Govt. of India (Grant No. DST/BHU/PURSE 2017-18 and DST/BHU/FIST 2016-17) for financial support. The authors declare that they do not have any other affiliations or financial involvement with any other organization or financial conflict with the subject matter or materials discussed in the manuscript apart from those disclosed. No writing assistance was utilized in the production of this manuscript.

\section{References}

Bogoch II, Watts A, Thomas-Bachli A, Huber C, Kraemer MU and Khan K (2020) Pneumonia of Unknown Etiology in Wuhan, China: Potential for International Spread Via Commercial Air Travel. J Travel Med 27(5): taaa008. DOI: $10.1093 / \mathrm{jtm} / \mathrm{taaa008}$.

Caly L, Druce JD, Catton MG, Jans DA and Wagstaff KM (2020) The FDA-approved drug ivermectin inhibits the replication of SARS-CoV-2 in vitro. Antiviral Res 178: 104787. DOI: $10.1016 /$ j.antiviral.2020.104787.

Chen M, Kappel M, Lemnge M, Bygbjerg IC and Theander TG (1994) In vitro effects of artesunate and other antimalarial agents on the function of human lymphocytes and neutrophils. In Transplantation Proceedings 26(6): 3172 3174. PMID: 7998107.

Duhovny D, Nussinov R and Wolfson HJ (2002) September. Efficient unbound docking of rigid molecules. In: International workshop on algorithms in bioinformatics. Springer, Berlin, Heidelberg, pp. 185-200. DOI: 10.1007/3-540-45784-4_14.

GaoY, Yan L, Huang Y, Liu F, Zhao Y, Cao L, Wang T, Sun Q, Ming Z, Zhang L and Ge J (2020) Structure of the RNAdependent RNA polymerase from COVID-19 virus. Science 368 (6492): 779-782. DOI: 10.1126/science.abb7498.

Gasteiger E, Gattiker A, Hoogland C, Ivanyi I, Appel RD and Bairoch A (2003) ExPASy: the proteomics server for indepth protein knowledge and analysis. Nucleic Acids Res 31(13): 3784-3788. DOI: $10.1093 / \mathrm{nar} / \mathrm{gkg} 563$.

Ho WE, Cheng C, Peh HY, Xu F, Tannenbaum SR, Ong CN and Wong WF (2012) Anti-malarial drug artesunate ameliorates oxidative lung damage in experimental allergic asthma. Free RadicBiol Med 53(3): 498-507. DOI: 10.1016/j.freeradbiomed.2012.05.021.

Huang B (2009) MetaPocket: a meta-approach to improve protein ligand binding site prediction, OMICS 13(4): 325-330. DOI: $10.1089 /$ omi.2009.0045.

Hui DS, Azhar EE, Madani TA, Ntoumi F, Kock R, Dar O, Ippolito G, Mchugh TD, Memish ZA, Drosten C and Zumla A (2020) The continuing epidemic threat of novel coronaviruses to global health-the latest novel coronavirus outbreak in Wuhang, China. Int J Infect Dis. DOI: 10.1016/j.ijid.2020.01.009. 
Imbert I, Guillemot JC, Bourhis JM, Bussetta C, Coutard B, Egloff MP, Ferron F, Gorbalenya AE and Canard B (2006) A second, non-canonical RNA-dependent RNA polymerase in SARS Coronavirus. EMBO J 25(20): 4933-4942. DOI: 10.1038/sj.emboj.7601368.

Kelley LA, Mezulis S, Yates CM, Wass MN and Sternberg MJ (2015) The Phyre2 web portal for protein modeling, prediction and analysis. Nat. Protoc 10(6): 845. DOI: $\underline{10.1038 / \text { nprot.2015.053 }}$

Kim S, Chen J, Cheng T, Gindulyte A, He J, He S, Li Q, Shoemaker BA, Thiessen PA, Yu B and Zaslavsky L (2019) PubChem 2019 update: improved access to chemical data. Nucleic Acids Res 47(D1): D1102-D1109. DOI: $10.1093 /$ nar/gky1033.

Kirchdoerfer RN and Ward AB (2019) Structure of the SARSCoV nsp12 polymerase bound to nsp 7 and nsp8 co-factors. Nat Commun 10(1): 1-9. DOI: 10.1038/s41467-01910280-3.

Laavola M, Nieminen R, Yam MF, Sadikun A, Asmawi MZ, Basir R, Welling J, Vapaatalo H, Korhonen R and Moilanen E (2012) Flavonoids eupatorin and sinensetin present in Orthosiphon stamineus leaves inhibit inflammatory gene expression and STAT1 activation. Planta Med 78(8): 77986. DOI: $10.1055 / \mathrm{s}-0031-1298458$.

Li G and De Clercq E (2020) Therapeutic options for the 2019 novel coronavirus (2019-nCoV). Nat Rev Drug Discov 19: 149-150. DOI: 10.1038/d41573-020-00016-0.

Li SW, Wang CY, Jou YJ, Huang SH, Hsiao LH, Wan L, Lin YJ, Kung SH and Lin CW (2016) SARS coronavirus papainlike protease inhibits the TLR7 signaling pathway through removing Lys63-linked polyubiquitination of TRAF3 and TRAF6. Int J Mol Sci 17(5): 678 (2016). DOI: $\underline{10.3390 / \mathrm{ijms} 17050678 .}$.

Liu Y, Wong VKW, Ko BCB, Wong MK and Che CM (2005) Synthesis and cytotoxicity studies of artemisinin derivatives containing lipophilic alkyl carbon chains. Org Lett 7(8): 1561-1564. DOI: $\underline{10.1021 / \mathrm{ol} 050230 \mathrm{o}}$.

Lv C, Liu W, Wang B, Dang R, Qiu L, Ren J, Yan C, Yang Z and Wang X (2018) Ivermectin inhibits DNA polymerase UL42 of pseudorabies virus entrance into the nucleus and proliferation of the virus in vitro and vivo. Antiviral Res 59: 55-62. DOI: 10.1016/j.antiviral.2018.09.010.

Razak NA, Abu N, Ho WY, Zamberi NR, Tan SW, Alitheen NB, Long K and Yeap SK (2019) Cytotoxicity of eupatorin in MCF-7 and MDA-MB-231 human breast cancer cells via cell cycle arrest, anti-angiogenesis and induction of apoptosis. Sci Rep 9(1): 1514. DOI: 10.1038/s41598-01837796-w.

Stothard P (2000) The sequence manipulation suite: JavaScript programs for analyzing and formatting protein and DNA sequences. Biotechniques 28(6): 1102-1104. DOI: $\underline{10.2144 / 00286 \mathrm{ir} 01 .}$.

Subissi L, Imbert I, Ferron F, Collet A, Coutard B, Decroly E and Canard B (2014) SARS-CoV ORF1b-encoded nonstructural proteins 12-16: replicative enzymes as antiviral targets. Antiviral Res 101: 122-130. DOI: 10.1016/j.antiviral.2013.11.006.

Wang M, Cao R, Zhang L, Yang X, Liu J, Xu M, Shi Z, Hu Z, Zhong W and Xiao G (2020) Remdesivir and chloroquine effectively inhibit the recently emerged novel coronavirus (2019-nCoV) in vitro. Cell Res 30(3): 269-271. DOI: 10.1038/s41422-020-0282-0.

Waterhouse A, Bertoni M, Bienert S, Studer G, Tauriello G, Gumienny R and Lepore R (2018) SWISS-MODEL: homology modelling of protein structures and complexes. Nucleic Acids Res 46(W1): W296-W303. DOI: 10.1093/nar/gky427.

Wiederstein M and Sippl MJ (2007) ProSA-web: interactive web service for the recognition of errors in three-dimensional structures of proteins. Nucleic Acids Res 35: W407-W410. DOI: $10.1093 / \mathrm{nar} / \mathrm{gkm} 290$.

World Health Organization (2020) Infection Prevention and Control During Health Care When Novel Coronavirus (nCoV) Infection Is Suspected. Interim Guidance 1-5.

Wu C, Liu Y, Yang Y, Zhang P, Zhong W, Wang Y, Wang Q, Xu Y, Li M, Li X and Zheng M (2020) Analysis of therapeutic targets for SARS-CoV-2 and discovery of potential drugs by computational methods. Acta Pharm Sin B 10(5): 766788. DOI: $10.1016 /$ j.apsb.2020.02.008.

Xu D and Zhang Y (2011) Improving the physical realism and structural accuracy of protein models by a two-step atomic-level energy minimization. Biophy $J$ 101(10): 2525-2534. DOI: 10.1016/j.bpj.2011.10.024.

Xu XW, Wu XX, Jiang XG, Xu KJ, Ying LJ, Ma CL, Li SB, Wang HY, Zhang S, Gao HN and Sheng JF (2020) Clinical findings in a group of patients infected with the 2019 novel coronavirus (SARS-Cov-2) outside of Wuhan, China: retrospective case series. BMJ 368: 606. DOI: 10.1136/bmj.m606.

Yang Y, Islam MS, Wang J, Li Y and Chen X (2020) Traditional Chinese medicine in the treatment of patients infected with 2019-new coronavirus (SARS-CoV-2): A review and perspective. Int J Biol Sci 16(10): 1708-1717. DOI: 10.7150/ijbs.45538.

Yao X, Ye F, Zhang M, Cui C, Huang B, Niu P, Liu X, Zhao L, Dong E, Song C, Zhan S, Lu R, Li H, Tan W and Liu D (2020) In vitro antiviral activity and projection of optimized dosing design of hydroxychloroquine for the treatment of severe acute respiratory syndrome coronavirus 2 (SARS-CoV-2). Clin Infect Dis 71(15): $732-$ 739. DOI: $10.1093 / \mathrm{cid} / \mathrm{ciaa} 237$.

Zhou D, Dai SM and Tong Q (2020) COVID-19: a recommendation to examine the effect of hydroxychloroquine in preventing infection and progression, JAntimicrob Chemother 75(7): 1667-1670. DOI: $10.1093 / \mathrm{jac} / \mathrm{dkaa} 114$.

Zhou G, Sirichaisinthop J, Sattabongkot J, Jones J, Bjornstad ON, Yan G and Cui L (2005) Spatio-temporal distribution of Plasmodium falciparum and $P$. vivax malaria in Thailand. Am J Trop Med Hyg 72: 256-262. DOI: 10.4269/ajtmh.2005.72.256. 
